\title{
Numerical Simulation of Coal Microwave Heating and Evaluation of The Reliability of The Results By Changing The Parameters Affecting It
}

\author{
Ali Jebelli \\ University of Alberta https://orcid.org/0000-0001-8364-3244 \\ Arezoo Mahabadi \\ University of Tehran \\ Rafiq Ahmad ( $\nabla$ rafiq.ahmad@ualberta.ca ) \\ University of Alberta https://orcid.org/0000-0001-9353-3380
}

\section{S.I. : Control of Coal Fire}

Keywords: COMSOL, Coal microwave heating, Coal permeability enhancement, Cavity

Posted Date: November 30th, 2021

DOI: https://doi.org/10.21203/rs.3.rs-1012734/v1

License: (c) (i) This work is licensed under a Creative Commons Attribution 4.0 International License.

Read Full License 


\title{
Numerical simulation of coal microwave heating and evaluation of the reliability of the results by changing the parameters affecting it
}

\author{
Ali Jebelli ${ }^{1}$, Arezoo Mahabadi ${ }^{2}$, Rafiq Ahmad ${ }^{1 *}$ \\ ${ }^{1}$ Laboratory of Intelligent Manufacturing, Design and Automation (LIMDA), Department of Mechanical Engineering, University \\ of Alberta, 9211116 Street NW, Edmonton, Canada \\ ${ }^{2}$ Department of Basic Engineering Science, Tehran University, Tehran, Iran \\ *Corresponding Author: rafiq.ahmad@ualberta.ca
}

In most mines, methane gas is accumulated in pores inside coal, the highest amount of which is found in coal mines, and methane is the most important polluting gas in underground coal mines. In coal mining operations, coalbed methane is one of the potential hazards that must be extracted to prevent an explosion of the accumulated gas and environmental pollution. One of the mechanisms is using microwave irradiation so that the thermal stress caused by microwave heating generates fractures. In this research, we investigated the most important parameters affecting the electric and thermal fields' distribution in coal in order to identify the effective parameters that achieve the highest temperature increase rate and to reach the highest impact and efficiency of the system with the least amount of consumed energy. The results of this study show that the most effective parameter on the electric and thermal fields' distribution within coal is the size of the resonance chamber.

Keywords: COMSOL, Coal microwave heating, Coal permeability enhancement, Cavity.

\section{Introduction}

It is crucial to extract methane gas before and during underground mining operations to prevent methane eruptions and accidents caused by coalbed methane (CBM) explosions in coal. However, maximizing the extraction process while minimizing the associated pollution is one of the most challenging issues this industry is facing. One of the most recent approaches for extracting this gas is the use of microwave radiations. Microwave radiations are widely used in coal processing fields such as drying, coking, pyrolysis, flotation, increasing grindability, and magnetic removal [1]. Microwaves are a type of electromagnetic waves, with frequencies between $300 \mathrm{MHz}$ and $300 \mathrm{GHz}$, widely used in industrial, scientific, medical, and instrumental applications. By increasing the permeability of coal, such waves affect the molecules and raise the object temperature by increasing the internal vibration of molecular bonds, lengthening these bonds, and enhancing the mobility of molecules and their internal energy [2]. Thus, the moisture in the coal evaporates under microwave radiation, and the water vapor pressure expands the pores and cracks of the coal with increasing heat [3].

The materials (liquid or solid) in the microwave cavity heats up rapidly under microwave radiation in response to strong interaction with an electric or magnetic field. Microwave ovens are very useful when they need to efficiently transfer energy to the reaction vessel, but only if they meet the following needs [4]:

1. The electric field profile must be homogeneous, either by using state stirrers or by rotating the reaction cavity itself.

2. The geometry of the reactor must be well designed considering the depth of microwave penetration.

3. The temperature and pressure inside the reaction chamber must be controlled for a continuous control of the process parameters.

4. The costs of reactor and spare parts must be considered.

5. Safety and leakage of microwaves must be considered.

In previous studies, limited parameters were considered when examining the electric field and heat of coal [5, 6]. Therefore, this study attempts to have a comprehensive study of the microwave effects on coal, without considering the limitations of previous experiments, by presenting a complete theory of the problem and examining the most important effective parameters. In the final step, the tests were repeated in a new chamber with different dimensions and the results successfully compared.

\section{Theory}


To measure the rate of heat absorption and transfer in a microwave chamber, we need to model the microwave propagation as well as the heat and mass transfer in the chamber.

\subsection{Symbols}

The list of symbols used in this paper are summarized in Table 1.

Table 1- Table of symbols.

\begin{tabular}{|c|c|c|c|c|c|}
\hline Name & $\begin{array}{l}\text { electric field intensity } \\
(\mathrm{V} / \mathrm{m})\end{array}$ & $\begin{array}{l}\text { magnetic field } \\
\text { intensity }(\mathrm{A} / \mathrm{m})\end{array}$ & $\begin{array}{l}\text { electric flux density } \\
(\mathrm{C} / \mathrm{m})\end{array}$ & $\begin{array}{l}\text { magnetic flux density } \\
(\mathrm{Wb} / \mathrm{m})\end{array}$ & $\begin{array}{l}\text { magnetic current } \\
\text { density }\left(\mathrm{V} / \mathrm{m}^{2}\right)\end{array}$ \\
\hline Symbol & $E$ & $\mathrm{H}$ & $\mathrm{D}$ & B & $\bar{M}$ \\
\hline Name & $\begin{array}{l}\text { electric current } \\
\text { density }\left(\mathrm{A} / \mathrm{m}^{2}\right)\end{array}$ & $\begin{array}{l}\text { electric charge density } \\
\left(\mathrm{C} / \mathrm{m}^{3}\right)\end{array}$ & permeability $(\mathrm{H} / \mathrm{m})$ & relative permeability & $\begin{array}{c}\text { permittivity } \\
(\mathrm{F} / \mathrm{m})\end{array}$ \\
\hline Symbol & $\mathrm{J}$ & $\mathrm{P}$ & $\mu$ & $\mu_{\mathrm{r}}$ & $\varepsilon$ \\
\hline Name & relative permittivity & $\begin{array}{c}\text { free space wave } \\
\text { number }\end{array}$ & conductivity & angular frequency & surface normal vector \\
\hline Symbol & $\varepsilon_{\mathrm{r}}$ & $\mathrm{k}_{0}$ & $\sigma$ & $\omega$ & $\mathrm{N}$ \\
\hline Name & density $\left(\mathrm{kg} / \mathrm{m}^{3}\right)$ & $\begin{array}{l}\text { specific heat capacity } \\
\text { at constant stress } \\
(\mathrm{J} /(\mathrm{kg} \cdot \mathrm{K}))\end{array}$ & $\begin{array}{l}\text { absolute temperature } \\
(\mathrm{K})\end{array}$ & heat source $\left(\mathrm{W} / \mathrm{m}^{3}\right)$ & $\begin{array}{c}\text { velocity vector of } \\
\text { translational motion } \\
(\mathrm{m} / \mathrm{s})\end{array}$ \\
\hline symbol & $\rho$ & $\mathrm{C}_{\mathrm{p}}$ & $\mathrm{T}$ & $\mathrm{Q}$ & $\mathrm{U}$ \\
\hline Name & heat flux $\left(\mathrm{W} / \mathrm{m}^{2}\right)$ & material's conductivity & time & $\begin{array}{l}\text { concentration of } \\
\text { species }\left(\mathrm{mol} / \mathrm{m}^{3}\right)\end{array}$ & $\begin{array}{c}\text { diffusion coefficient } \\
\left(\mathrm{m}^{2} / \mathrm{s}\right)\end{array}$ \\
\hline Symbol & $q$ & $\mathrm{k}$ & $\mathrm{t}$ & $\mathrm{c}$ & $\mathrm{D}_{\mathrm{c}}$ \\
\hline Name & $\begin{array}{c}\text { mass averaged } \\
\text { velocity vector }(\mathrm{m} / \mathrm{s})\end{array}$ & $\begin{array}{l}\text { reaction rate for the } \\
\text { species }\left(\mathrm{mol} /\left(\mathrm{m}^{3} \cdot \mathrm{s}\right)\right)\end{array}$ & $\begin{array}{l}\text { diffusive flux vector } \\
\qquad\left(\mathrm{mol} /\left(\mathrm{m}^{2} \cdot \mathrm{s}\right)\right.\end{array}$ & Cutoff frequency & Speed of light \\
\hline Symbol & $\mathrm{u}$ & $\mathrm{R}$ & $\mathrm{J}_{\mathrm{m}}$ & $\mathrm{fc}$ & $\mathrm{C}_{0}$ \\
\hline Name & wavelength & Rayleigh number & length & $\begin{array}{c}\text { dynamic viscosity } \\
(\mathrm{kg} / \mathrm{m} . \mathrm{s})\end{array}$ & $\begin{array}{c}\text { mass transfer } \\
\text { coefficient }\end{array}$ \\
\hline Symbol & $\lambda$ & $\mathrm{Ra}_{\mathrm{L}}$ & $\mathrm{L}$ & $\mathrm{v}$ & $\mathrm{k}_{\mathrm{c}}$ \\
\hline Name & moisture conductivity & $\begin{array}{l}\text { specific moisture } \\
\text { capacity }\end{array}$ & & & \\
\hline Symbol & $\mathrm{k}_{\mathrm{m}}$ & $\mathrm{C}_{\mathrm{m}}$ & & & \\
\hline
\end{tabular}

In this research, " $\nabla$ " denotes the gradient, " $\nabla$. ." indicates divergence, and " $\nabla \times$ " states for the curl operator.

\subsection{Maxwell Equations}

Solving any electromagnetic problem requires solving Maxwell's equations, which consist of four basic equations that link between the electric field $\mathrm{E}$ and the magnetic field $\mathrm{B}$. Their differential form is as follows [7-9]:

$\nabla \times \bar{E}(t)=-\frac{\partial \bar{B}}{\partial t}-\bar{M}$

(1), $\quad \nabla \times \bar{H}(t)=-\frac{\partial \bar{D}}{\partial t}-\bar{J}$

$\nabla \cdot \bar{D}=P$

(3), $\quad \nabla \cdot \bar{B}=0$

with

$B=\mu . H$

(5), $\quad D=\varepsilon . E$

Here $\varepsilon=\varepsilon_{0} \varepsilon_{\mathrm{r}}$ and $\mu=\mu_{0} \mu_{\mathrm{r}}$ stand respectively for the permittivity and permeability of the medium of propagation, with $\varepsilon_{0}=8.85^{*} 10^{-12} \mathrm{~F} / \mathrm{m}$ and $\mu_{0}=4 \pi^{*} 10^{-7} \mathrm{H} / \mathrm{m}$ the respective permeability and permittivity of free space[10]. The magnetic and electric current densities (respectively $\mathrm{M}$ and $\mathrm{J}$ ) as well as the electric charge density $\rho$ are the sources of the fields and are function of location.

According to (1) to (6), the Maxwell equation governing the electromagnetic waves inside the microwave chamber is as follows [11]: 
$\nabla \times \mu_{r}^{-1}(\nabla \times E)-k_{0}^{2}\left(\varepsilon_{r}-\frac{j \sigma}{\omega \varepsilon_{0}}\right) E=0$

\subsection{Heat transfer}

Heat transfer in materials can be achieved by different ways. In fluids, heat is often transferred by convection, in which case the movement of the fluid itself transfers heat from one place to another [12]. Conduction is another method to transfer heat, in which there is no movement of the material and it is done by the transfer of energy within that material in contact with another material. The third way to transmit energy is by radiation, which involves the absorption or irradiation of electromagnetic waves.

According to Fourier's law of heat transfer, in a continuous environment, the conductive heat flux ( $\left.\mathrm{q}_{\text {cond }}\right)$ is proportional to the temperature gradient:

$q_{\text {cond }}=-k . \nabla T$

According to Newton's Law of cooling, the convective heat flux depends on the temperature difference between the object surface and the environment (the fluid around the object).

$q_{\text {conv }}=h A_{s}\left(T_{\text {surface }}-T_{\text {fluid }}\right)$

The heat exchange rate of pure radiation can be expressed as follows:

$q_{\text {rad }}=\alpha \beta A_{s}\left(T_{\text {surface }}-T_{s}\right)$

Where $0<\alpha<1$ and $\beta=5.67 * 10^{-8} \mathrm{~W} / \mathrm{m}^{2} K^{4}$

The rate of increase of object temperature in a non-uniform isotropic medium is obtained by solving the following equation $[13,14]$ :

$\rho C_{p} \frac{\partial T}{\partial t}+\rho C_{p} \bar{u} \cdot \nabla T+\nabla \cdot(q)=Q_{v a p}+Q_{M W}$

where $\mathrm{q}$ includes the conduction heat flux and the radiant heat flux:

$q=q_{\text {rad }}+q_{\text {cond }}$

Here, $\mathrm{Q}_{\mathrm{vap}}$ is the latent heat of evaporation of coal moisture and $\mathrm{Q}_{\mathrm{Mw}}$ is the heat from microwave radiation. The heat entering the specimen consists of two parts: dielectric losses and magnetic losses:

$Q_{M W}=Q_{r h}+Q_{m l}$

$Q_{\mathrm{rh}}$ is the heat that enters the object due to losses of electric field and it is defined as real part (Re) of dot product between electric current density vector and complex conjugate of electric field intensity vector:

$Q_{r h}=\frac{1}{2} \operatorname{Re}\left(\boldsymbol{J} \cdot \boldsymbol{E}^{*}\right)$

while $\mathrm{Q}_{\mathrm{ml}}$ is the heat that enters the object due to the losses of the magnetic field and it is calculated as follows [11]

$Q_{m l}=\frac{1}{2} \operatorname{Re}\left(j \omega \boldsymbol{B} \cdot \boldsymbol{H}^{*}\right)$

\subsection{Mass transfer}

Mass transfer examines the transfer of matter due to differences in chemical potential; the net mass movement of a species from a higher concentration area to a lower one is called mass transfer. Therefore, it is essential to have two areas with different chemical structures for mass transfer. The term is commonly used in engineering for physical processes, which includes the diffusion of particles and the convection of chemical species in physical systems. Thus, the convection-diffusion equation is used to investigate this phenomenon. According to Fick's law that expresses the diffusion phenomenon, the general form of the convection-diffusion equation is as follows: 
$\frac{\partial \mathrm{c}}{\partial \mathrm{t}}+\nabla \cdot \bar{\jmath}_{m}+\bar{u} \cdot \nabla c=R$

(16), $\quad \bar{J}_{m}=-D_{c} \nabla c$

$\nabla . \bar{\jmath}_{m}$ describes diffusion, $\bar{u} . \nabla c$ describes convection (when coupled to fluid flow) and the reaction rate $\mathrm{R}$ describes the creation or destruction of the quantity. For example, R describes how the molecule can be created or destroyed by chemical reactions.

The diffusion coefficient is calculated as follows:

$D_{c}=\frac{k_{m}}{\rho C_{m}}$

\subsection{System design}

The cutoff frequency is the minimum frequency of a wave that can propagate in a waveguide. The cutoff frequency depends on the dimensions of the waveguide. For a rectangular waveguide with width w and height h, the TEmn mode cut-off frequency is calculated as follows:

$f_{C_{0}, m, n}=\frac{C_{0}}{2} \sqrt{\left(\frac{m}{w}\right)^{2}+\left(\frac{n}{h}\right)^{2}}, \mathrm{~m}, \mathrm{n}=0,1, \ldots$

Dimensions are usually designed in such a way that $\mathrm{TE}_{10}$ mode is used in rectangular waveguides [15]. In a cubic cavity with width $w$, depth $d$ and height $h$, the resonance frequency is calculated as follows [16]:

$f_{\text {res }}=\frac{c_{0}}{2} \sqrt{\left(\frac{m}{w}\right)^{2}+\left(\frac{n}{h}\right)^{2}+\left(\frac{p}{d}\right)^{2}}, m, n, p=0,1,2, \ldots$

\subsection{Initial conditions}

The following initial conditions have been considered:

1. The initial temperature of all objects is equal to the ambient temperature of $293.15 \mathrm{~K}$

2. The initial electric field is zero

3. The initial moisture concentration of coal is $3394.4 \mathrm{~mol} / \mathrm{m}^{3}$

4. $\mathrm{TE}_{10}$ mode is the dominant mode for the rectangular waveguide used in the study [15]

\subsection{Boundary conditions}

The impedance boundary condition is considered for the walls of the microwave chamber and the waveguide. Its governing equation is as follows [11]:

$\sqrt{\frac{\mu_{0} \mu_{r}}{\epsilon_{0} \epsilon_{r}-j \frac{\sigma}{\omega}}} n \times H+E-(n . E) n=0$

We assumed that there is no heat transfer from the glass plate to the specimen and the loss of electric waves in the specimen is the only reason for the increase in specimen temperature, so the boundary condition between the specimen and the glass plate is defined as follows[17]:

n. $(-k \nabla T)=0$

However, natural convection is considered for specimen walls: 


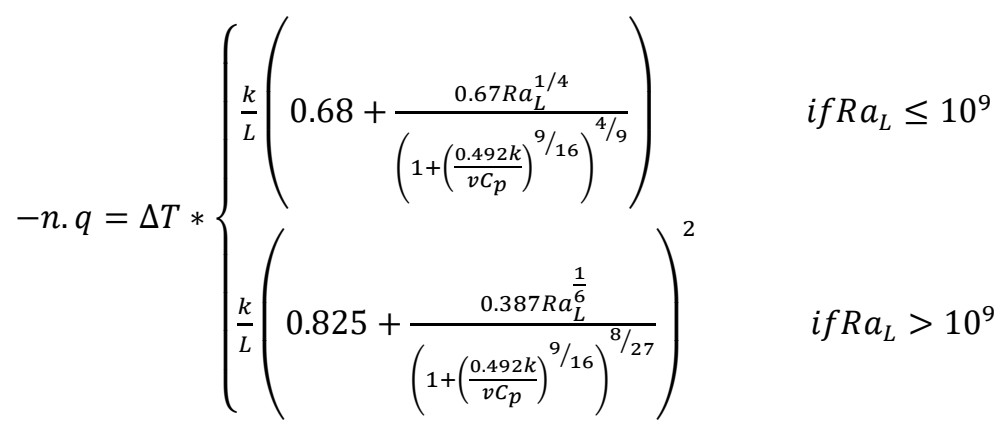

Also, there is no mass flux at the boundary between the specimen and the plate, so the boundary conduction condition between the specimen and the plate is defined as follows:

$n \cdot \bar{J}_{m}=0$

The mass flux of other specimen boundaries is defined as follows:

$n \cdot \bar{J}_{m}=k_{c}\left(c_{a i r}-c\right)$

where $\mathrm{c}$ denotes moisture concentration.

\subsection{Assumptions}

The following assumptions are considered to simplify the designed problem:

1. The microwave only heats the specimen placed inside it and has no effect on the air or the glass container on which the specimen is placed.

2. The wall material is assumed to be copper

3. The specimens placed in the microwave oven are isotropic and homogeneous

4. The electrical, magnetic and thermal properties of coal are constant

5. The motion of water molecule in magnetic and electric field is simplified as a fixed mass transfer

6. The chemical reaction of objects is ignored (the ignition temperature of coal is $360^{\circ} \mathrm{C}$ [18])

\section{Methodology}

In this simulation, using the COMSOL software, the electromagnetic part of the equation is first solved. In other words, Maxwell equations are solved using the physics of electromagnetic waves in their frequency range, and the microwave propagation and the amount of wave loss inside the microwave is obtained. The values of dielectric losses is the amount of energy absorbed in the specimen. The temperature distribution of the specimen and its heat transfer to the environment is obtained using the Fourier equation in the time domain. By calculating the mass transfer in coal, we simulated the changes in coal moisture.

To start the simulation of the device, a microwave device is first defined with the specifications reported in Table 2; the height of the microwave port from its lower surface is equal to $94 \mathrm{~mm}$ [3].

Table 2- Microwave and coal model sizes.

\begin{tabular}{|c|c|c|c|c|}
\hline & Width $(\mathrm{mm})$ & Depth $(\mathrm{mm})$ & Height $(\mathrm{mm})$ & Radius $(\mathrm{mm})$ \\
\hline Microwave oven & 267 & 270 & 188 & - \\
\hline Waveguide & 50 & 78 & 18 & - \\
\hline Glass plate & - & - & 6 & 113.5 \\
\hline Sample & - & - & 60 & 25 \\
\hline
\end{tabular}




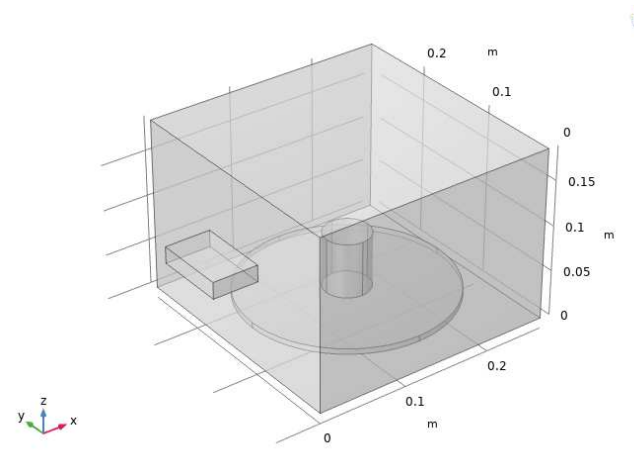

Figure 1- Microwave system defined with a cylindrical specimen inside.

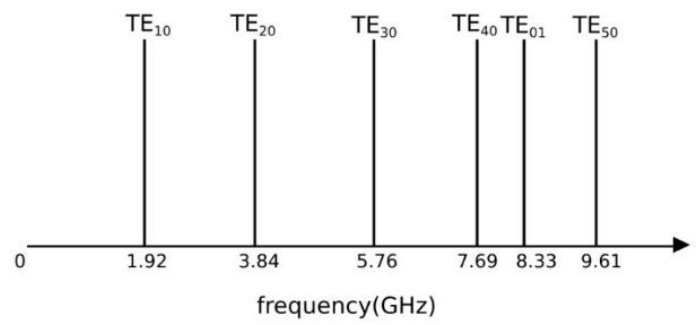

Figure 2- Frequency sequence of propagating modes in the used rectangular waveguide according to Table 3. In rectangular waveguide TE and TM mode calculation is the same.

Figure 1 shows the defined standard cavity and the coal sample inside it. As shown in the figure 2, the bandwidth of the waveguide is defined in the frequency range of $1.92 \mathrm{GHz}$ to $3.84 \mathrm{GHz}$. According to the rule of thumb, the total number of geometry elements is 77,000 with an average element quality of $70 \%$. If the maximum system frequency of $4 \mathrm{GHz}$ equivalent to the maximum element size of $15 \mathrm{~mm}$ in a vacuum is considered, such quality will be achieved in meshing [19]. Figure 3 shows the optimal mesh quality and reliability of the results. The selected material of the system is identified in Table 3.

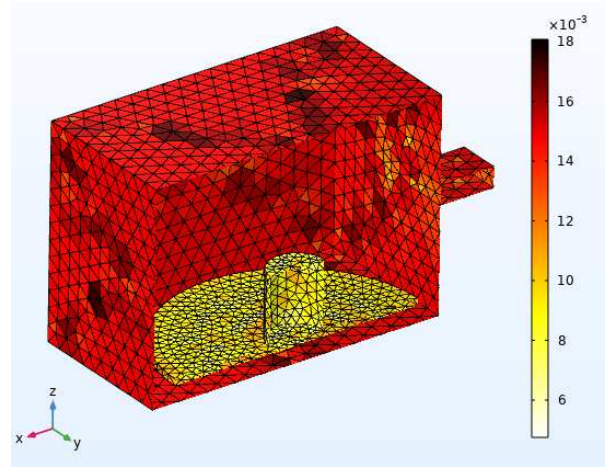

Figure 3- System meshing.

Table 3- Specifications of materials at 293.15K [5-20]. In this table, ( $\left.\varepsilon^{\prime}, \varepsilon^{\prime \prime}\right)$ and ( $\mu$ ', $\mu$ ") stand for the (real part, imaginary part) of the relative permittivity and permeability, respectively.

\begin{tabular}{|c|c|c|c|c|c|}
\hline Name & Units & \multicolumn{4}{|c|}{ Values } \\
\hline & & Coal & Glass & Copper & Air \\
\hline Relative permittivity $\left(\varepsilon^{\prime}-\mathrm{j} \varepsilon^{\prime \prime}\right)$ & - & Variable & 2.55 & 1 & 1 \\
\hline Relative permeability $\left(\mu{ }^{\prime}-\mathrm{j} \mu^{\prime \prime}\right)$ & - & 1 & 1 & 1 & 1 \\
\hline Electrical conductivity & $\mathrm{S} / \mathrm{m}$ & 0.02 & 0 & $5.998^{*} 10^{7}$ & 0 \\
\hline Thermal conductivity & $\mathrm{W} /(\mathrm{m} . \mathrm{k})$ & 0.478 & - & 400 & 0.0256 \\
\hline
\end{tabular}




\begin{tabular}{|c|c|c|c|c|c|}
\hline Density & $\mathrm{Kg} / \mathrm{m}^{3}$ & 1300 & - & 8960 & 1.204 \\
\hline Heat capacity at constant pressure & $\mathrm{J} /(\mathrm{kg} . \mathrm{K})$ & 4186.8 & - & 385 & 1015.1 \\
\hline
\end{tabular}

\section{Tests and simulations}

In this study, the effects of six cases of coal moisture capacity, operation frequency, input power and energy, specimen location in the microwave and the size and placement of the input waveguide were investigated on the intensity and distribution of the electric and thermal fields of coal. Generally, the applied power and operating frequency are respectively $1 \mathrm{~kW}$ and $2.45 \mathrm{GHz}$ in the tests, the coal specimens with a moisture capacity of $4.7 \%$ are placed in the microwave for 300 seconds, and each parameter is changed one at a time while the others are kept fixed. In Figure 4, the electric and thermal fields inside the chamber and the coal are for a moisture capacity of the coal of $4.7 \%$, an operating frequency of $2.45 \mathrm{GHz}$, an input power of $1 \mathrm{~kW}$, and a heating time of 300 seconds.

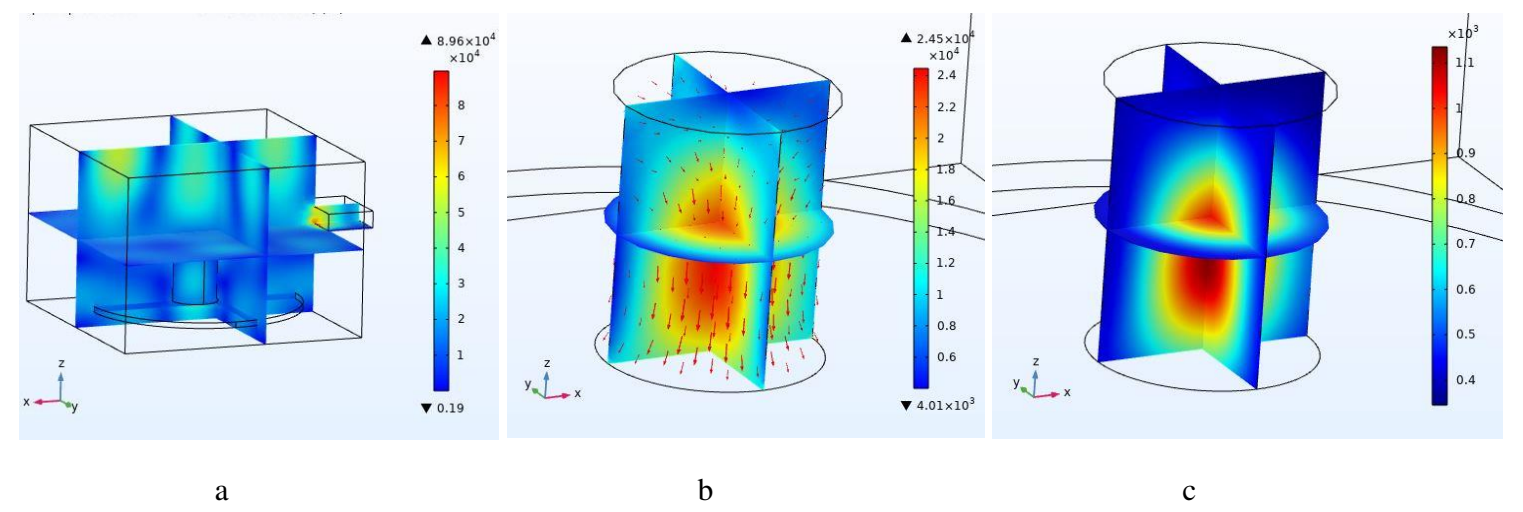

Figure 4- a) Electric field inside the chamber b) Electric field inside the coal c) Temperature inside the coal (K).

\subsection{Coal moisture capacity}

The simulated results in Table 4 show that the moisture capacity of coal has a linear effect on the permittivity of coal. Also, due to the constant input power for different specimens, the moisture diffusion coefficient in coal only depends on the moisture capacity of the coal [3].

Table 4- Diffusion coefficient and permittivity of coal specimens based on their specific moisture capacity.

\begin{tabular}{|c|c|c|c|c|c|c|c|c|c|c|c|c|}
\hline $\begin{array}{c}\text { Specific } \\
\text { moisture } \\
\text { capacity } \\
\left(\mathbf{C}_{\mathrm{m}} \%\right)\end{array}$ & 0.5 & 1 & 2 & 3 & 4 & 4.7 & 5 & 6 & 7 & 8 & 9 & 10 \\
\hline $\begin{array}{c}\text { Real } \\
\text { permittivity } \\
(\varepsilon ')\end{array}$ & 0.578 & 0.852 & 1.401 & 1.949 & 2.498 & 2.882 & 3.046 & 3.595 & 4.143 & 4.692 & 5.240 & 5.789 \\
\hline $\begin{array}{c}\text { Imaginary } \\
\text { permittivity } \\
(\varepsilon ")\end{array}$ & 0.161 & 0.178 & 0.211 & 0.245 & 0.278 & 0.301 & 0.311 & 0.345 & 0.378 & 0.411 & 0.444 & 0.478 \\
\hline $\begin{array}{c}\text { Diffusion } \\
\text { Coefficient } \\
(\mathrm{D} \mathrm{m} / \mathrm{s})\end{array}$ & $* 1.47$ & $\begin{array}{c}7.37 \\
* 10^{-3}\end{array}$ & $\begin{array}{c}3.69 \\
* 10^{-3}\end{array}$ & $\begin{array}{c}2.46 \\
* 10^{-3}\end{array}$ & $\begin{array}{c}1.84 \\
* 10^{-3}\end{array}$ & $\begin{array}{c}1.57 \\
* 10^{-3}\end{array}$ & $\begin{array}{c}1.47 \\
* 10^{-3}\end{array}$ & $\begin{array}{c}1.23 \\
* 10^{-3}\end{array}$ & $* 10^{-3}$ & $* 10^{-4}$ & $* 10^{-4}$ & $* 10^{-4}$ \\
\hline
\end{tabular}

Figures 5 and 6 show the effect of increasing coal moisture on the size and diffusion of the electric and thermal fields. As can be seen in these figures, the moisture capacity of coal has a significant effect on the electric field distribution in the cavity, the intensity of the electric and thermal fields in coal; also, the coal with a moisture capacity of 5\% has the highest average temperature and the highest temperature increase rate compared to the tested samples. 


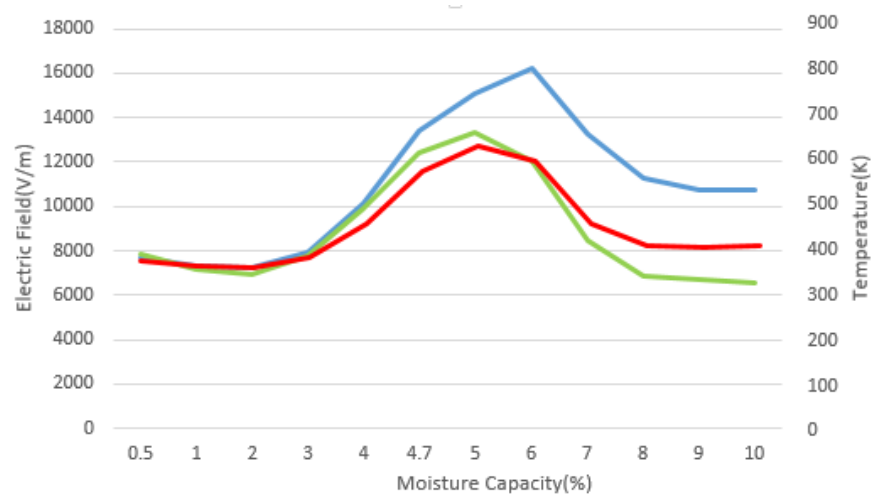

Figure 5- In this figure, the green line indicates the average electric field inside the coal, the blue line presents the average electric field inside the entire cavity, and the red line denotes the average temperature inside the coal.

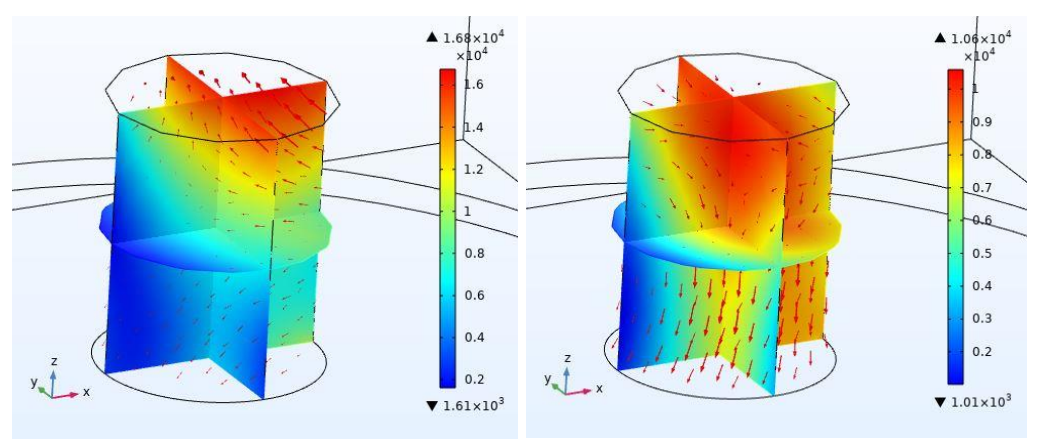

a

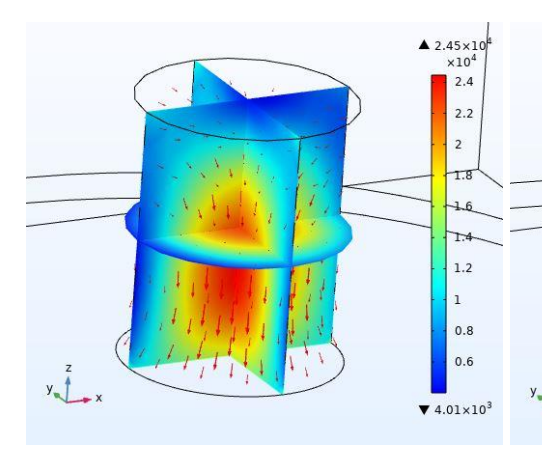

d b

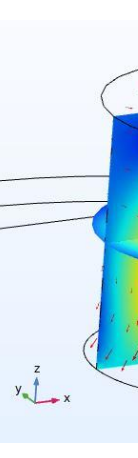

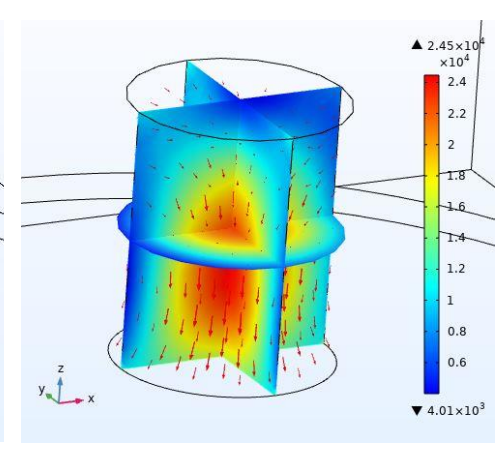

c

Figure 6- Electric field inside coal with the moisture capacity of a) $0.5 \%$ b) $2 \%$ c) $4.7 \%$ d) $5 \%$ e) $7 \%$ f) $10 \%$.

\subsection{Effect of microwave operating frequency}

Figure 7 shows the effect of frequencies 1.9 to $3.8 \mathrm{GHz}$ applied at a distance of $0.1 \mathrm{GHz}$ on the electric and thermal field inside the coal specimen. According to Figure 7, the frequency of $2.4 \mathrm{GHz}$ has the highest rate of temperature increase and $3 \mathrm{GHz}$ has the lowest rate of temperature increase in coal.

Also, there is the most uniform scattering of electric and thermal fields in coal at a frequency of $2 \mathrm{GHz}$, and there is the highest density of electric and thermal fields in coal at a frequency of $2.9 \mathrm{GHz}$. 


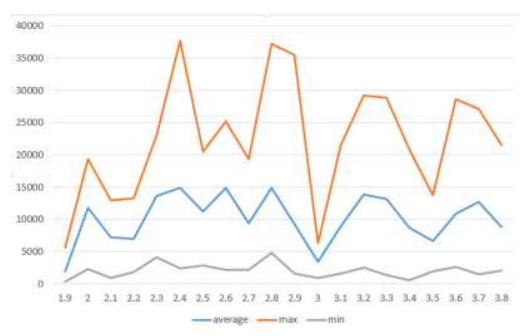

a

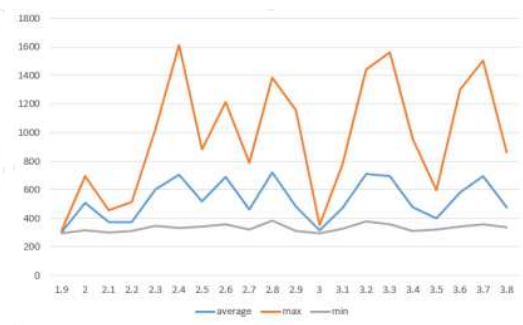

b

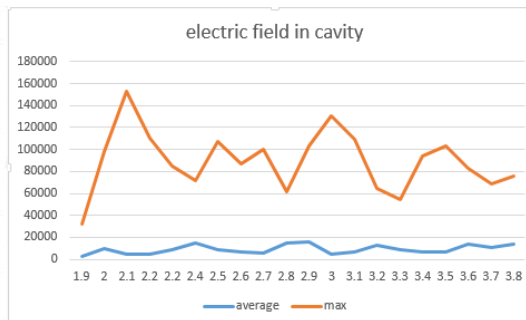

$\mathrm{C}$

Figure 7- a) Average, maximum, and minimum electric field in the specimen in the frequency range of 1.9 to $3.8 \mathrm{GHz}$ b) Average, maximum and minimum temperature in the coal specimen in the frequency range of 1.9 to $3.8 \mathrm{GHz}$ c) Maximum and average electric field in the cavity.

Figures 8 and 9 show four different frequencies 2, 2.4, 2.9 and $3 \mathrm{GHz}$.

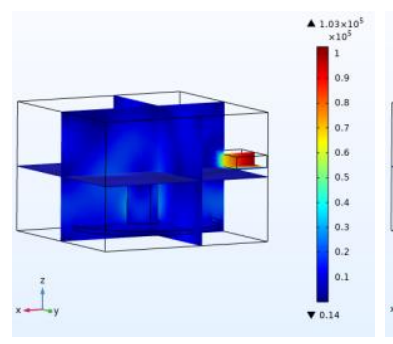

a

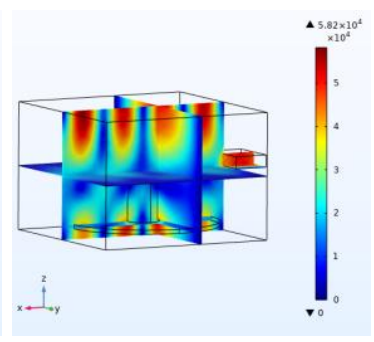

$\mathrm{b}$

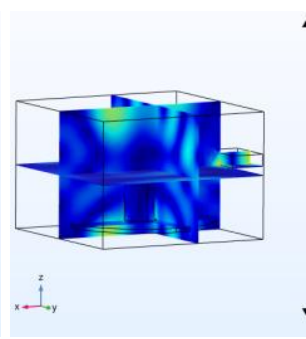

$\mathrm{c}$

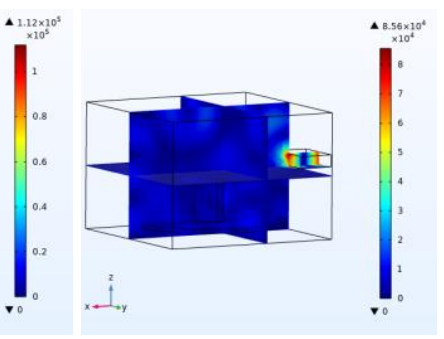

d

Figure 8- Electric field inside the cavity at a frequency of a) $2 \mathrm{GHz}$ b) $2.4 \mathrm{GHz}$ c) $2.9 \mathrm{GHz}$ d) $3 \mathrm{GHz}$.

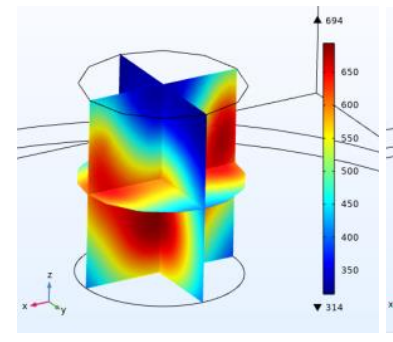

a

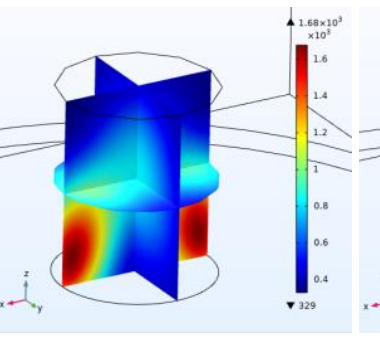

b

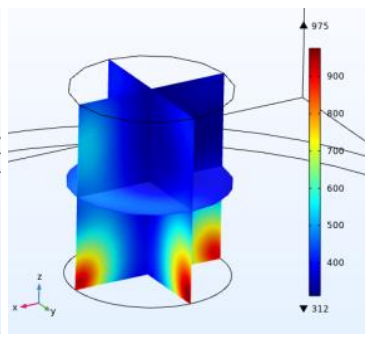

$\mathrm{c}$

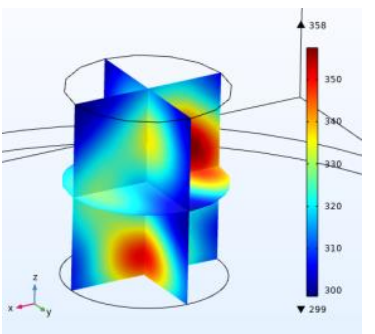

d

Figure 9- Coal temperature at frequency of a) $2 \mathrm{GHz}$ b) $2.4 \mathrm{GHz}$ c) $2.9 \mathrm{GHz}$ d) $3 \mathrm{GHz}$.

\subsection{Effect of the microwave power and heating time}

This section addresses the effect of input power on the electric and thermal fields of the system. According to the following relationship, the input power affects moisture conductivity and mass transfer coefficient, which are the effective parameters in mass transfer inside the specimen [3].

$k_{m}=0.01084 *$ Power -1.25

$k_{c}=10.7194 * k_{m}$

To make the specimens thermally comparable, the input energy is considered constant and equal to $300 \mathrm{~kJ}$ (Table 5). According to Figures 10 and 11, the electric field distribution does not depend on the amount of input power and only the size of the electric field increases in proportion to the square root of the input power [21]. The input power also affects the rate of increase of coal temperature by affecting the size of the electric field, and despite the constant input energy to the system, the final temperature of coal with an input power of $3 \mathrm{~kW}$ is higher. 
Table 5- Input power and heating time of coal (The input energy is $300 \mathrm{~kJ}$ in all tests)

\begin{tabular}{|c|c|c|c|c|c|c|c|}
\hline Parameter & Unit & \multicolumn{5}{|c|}{ Value } \\
\hline Power & W & 500 & 1000 & 1500 & 2000 & 2500 & 3000 \\
\hline Time & s & 600 & 300 & 200 & 150 & 120 & 100 \\
\hline
\end{tabular}

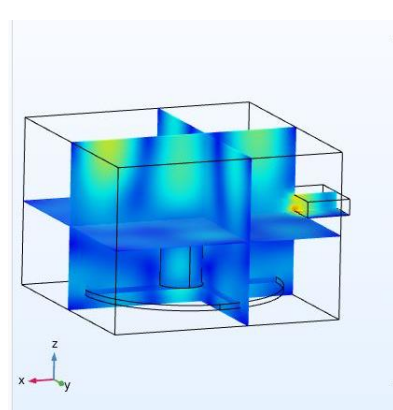

a
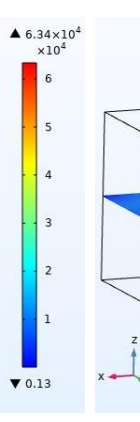

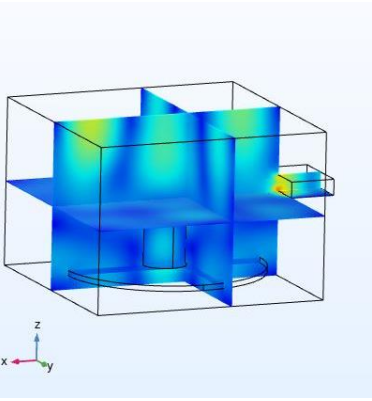

b

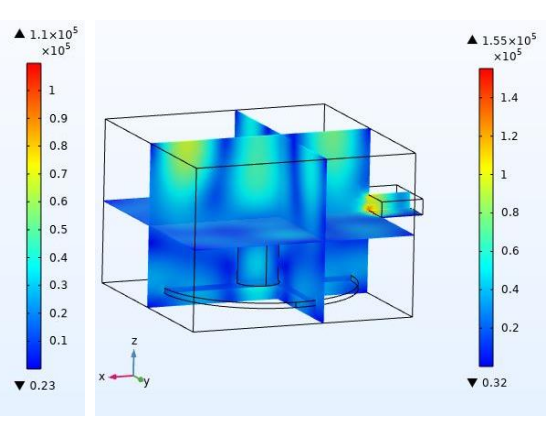

c

Figure 10- Electric field inside the cavity with an input port power of a) 500 watts b) 1500 watts c) 3000 watts.

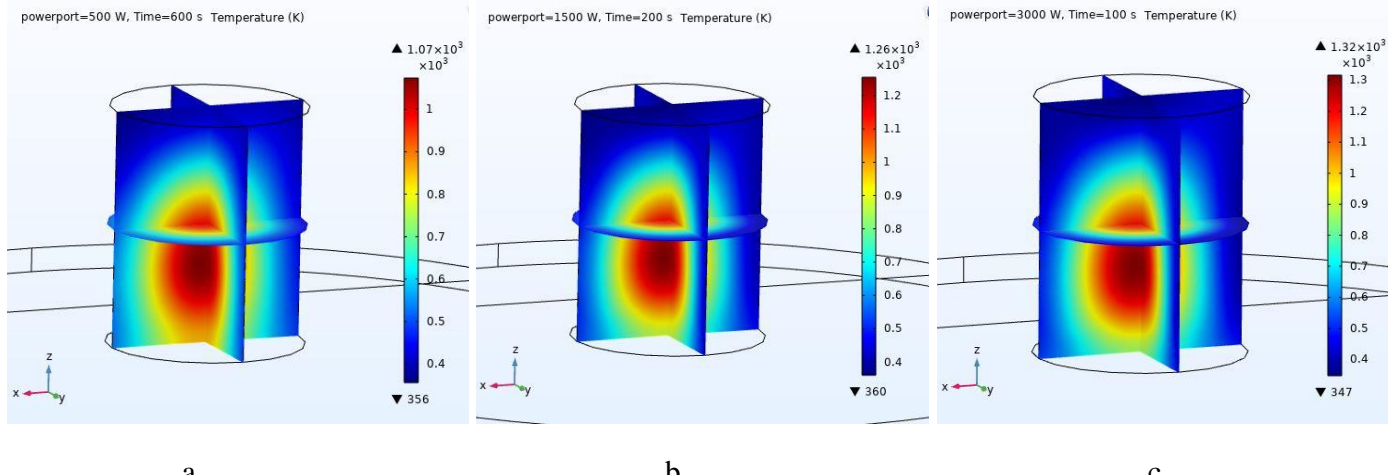

a

b

c

Figure 11- Temperature inside coal with input port power a) 500 watts b) 1500 watts c) 3000 watts.

\subsection{Effect of the waveguide port location}

In this section, the height of the waveguide port, which was set to $0.094 \mathrm{~m}$ in the previous experiments, was varied. Figure 12 shows the effect of increasing the height of the microwave port on the maximum and average electric field of the cavity and coal. Figure 13 also shows the distribution of electric and thermal fields at the height of $0.017,0.034$, 0.102 , and 0.136 meters. The height of 0.136 has the highest rate of temperature increase and height $0.034 \mathrm{~m}$ has the lowest rate of temperature increase and leads to the most uniform distribution of electric and thermal field inside the coal.

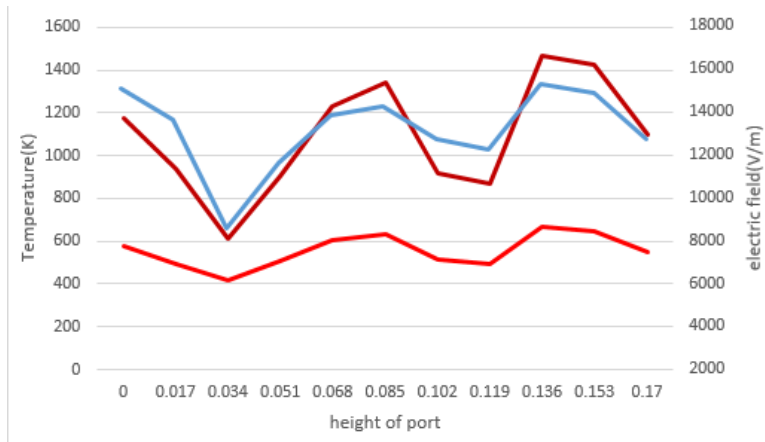


Figure 12- a) The effect of increasing the height of the microwave port with a step of $0.017 \mathrm{~m}$ on the average electric field inside the cavity (blue), maximum coal temperature (brown) and average coal temperature (red).
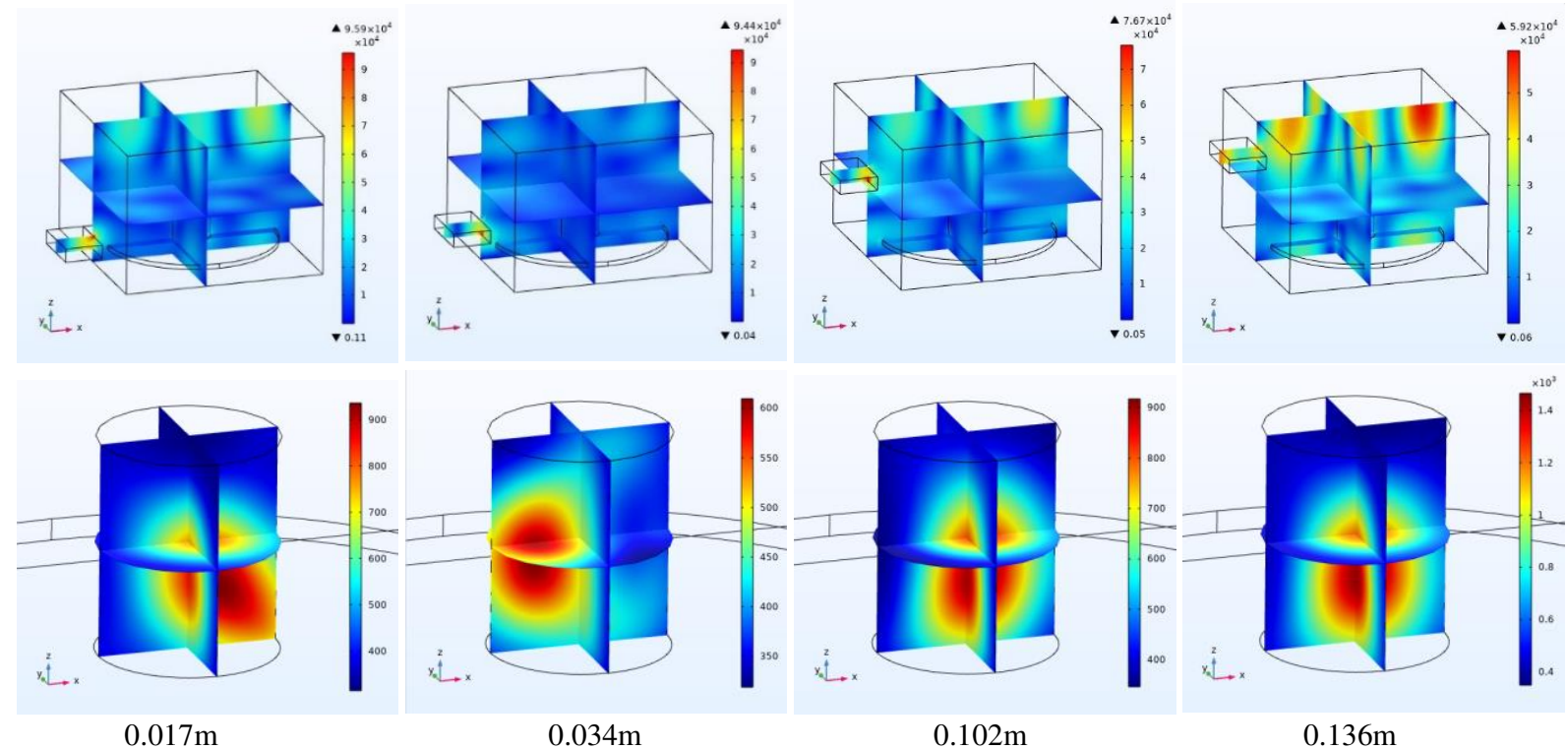

Figure 13- Electric field inside the chamber and temperature inside the coal due to the change in the height of the waveguide port.

\subsection{Effect of the waveguide chamber size}

The dimensions of the waveguide were varied one at a time to investigate the effect of the waveguide size. The dimensions of the waveguide have been changed according to Table 6.

Table 6- 5 different waveguides with different dimensions and sizes.

\begin{tabular}{|c|c|c|c|c|c|}
\hline Waveguide & 1 & 2 & 3 & 4 & 5 \\
\hline width $(\mathrm{m})$ & 0.078 & 0.078 & 0.078 & 0.064 & 0.091 \\
\hline Height $(\mathrm{m})$ & 0.018 & 0.039 & 0.018 & 0.018 & 0.018 \\
\hline Depth $(\mathrm{m})$ & 0.05 & 0.05 & 0.1 & 0.05 & 0.05 \\
\hline
\end{tabular}

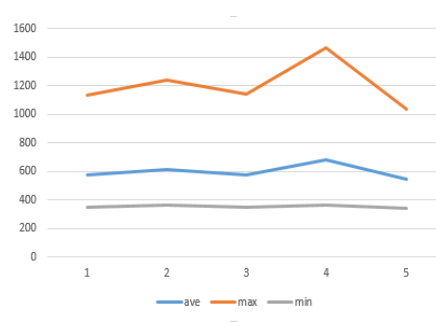

a

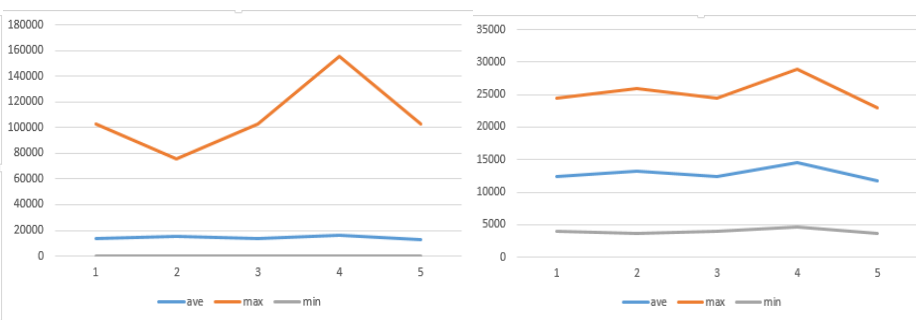

b

Figure 14- a) Average, maximum and minimum electric field in coal b) Electric field in the whole cavity c) Average, maximum and minimum heat field in coal. 


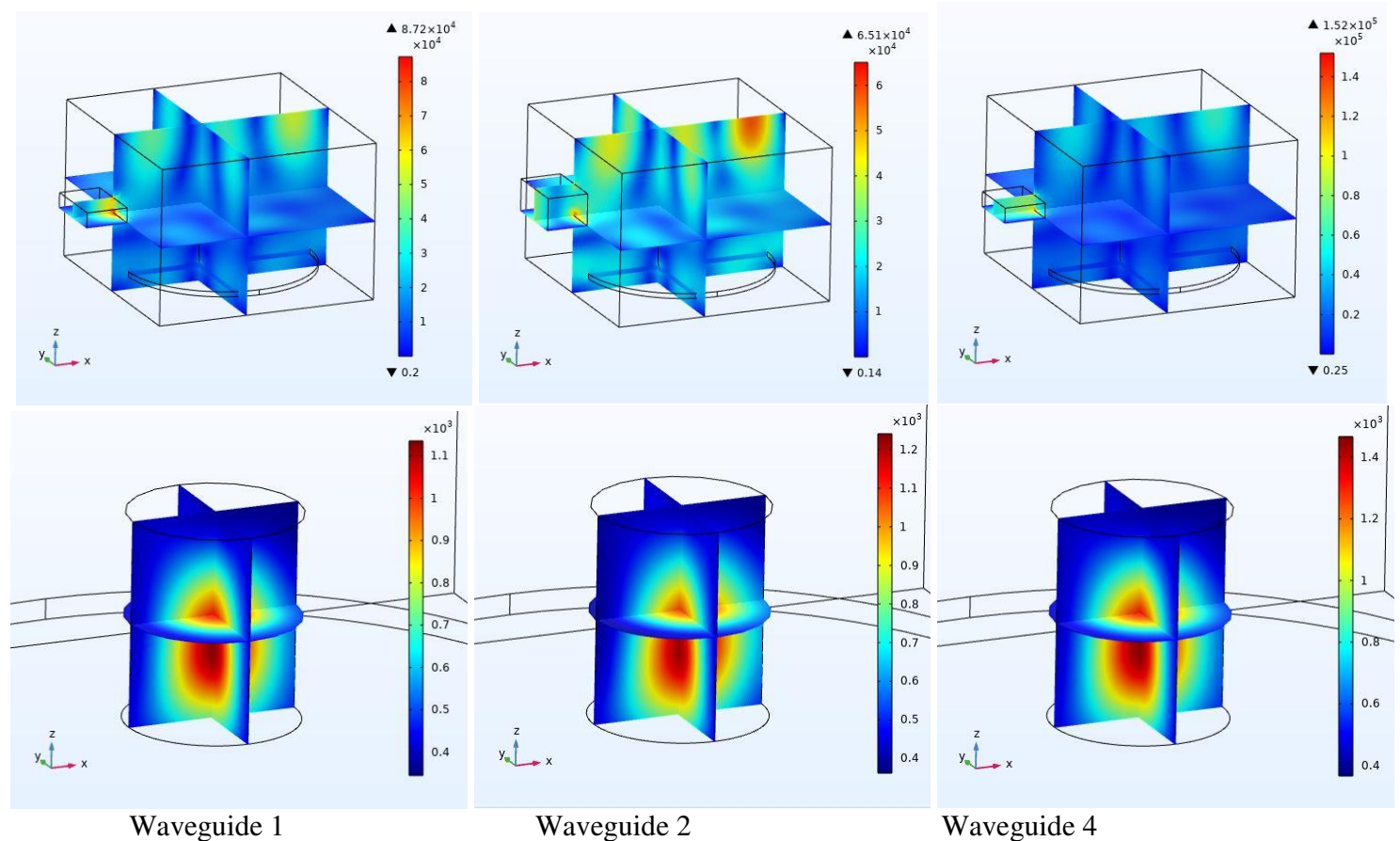

Figure 15- Electric field of the cavity with waveguides No. 1, 2, and 4 and heat field in coal corresponding to waveguides No. 1, 2 , and 4.

According to Figures 14 and 15, the distribution of the electric field inside the cavity does not change significantly by changing the dimensions of the waveguide. However, because the waveguide width and height affects the cutoff frequency of the waveguide, the waveguide acts as a highpass filter [22], and the length (depth) of the waveguide only affects the filtering of frequencies below the cutoff frequency. Moreover, when the cutoff frequency of the waveguide is close to the operating frequency $(2.45 \mathrm{GHz})$, the value of the electric field in the cavity and coal and, consequently, the rate of temperature increase inside the coal increases. As can be seen in Figure 16, the electric field inside the cavity and the average temperature inside the coal decrease.

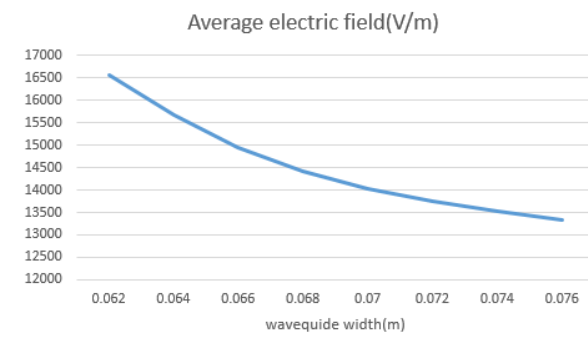

a

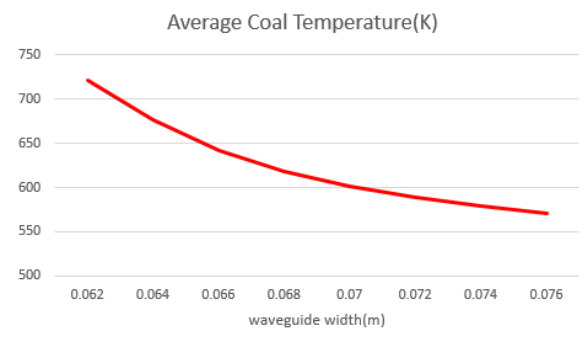

$\mathrm{b}$

Figure 16- a) Average electric field inside the chamber relative vs. waveguide width b) Average temperature inside coal vs. waveguide width.

\subsection{Place of Coal}

Another factor that can affect the distribution of electric field and heat inside the chamber is the location of the coal inside it. The average magnitude of the electric field for different heights of the coal bottom (z) and distances of the coal from the waveguide $(\mathrm{x})$ are reported in Table 7.

According to Figure 17, the highest average temperature, the most uniform thermal field, and the densest thermal field have been obtained for $(\mathrm{x} 2, \mathrm{z} 4),(\mathrm{x} 2, \mathrm{z} 2)$ and $(\mathrm{x} 1, \mathrm{z} 3)$, respectively.

Table 7- Average electric field in terms of coal displacement. 


\begin{tabular}{|c|c|c|c|c|c|c|}
\hline & $\mathrm{z} 1=0.022$ & $\mathrm{z} 2=0.042$ & $\mathrm{z} 3=0.062$ & $\mathrm{z} 4=0.082$ & $\mathrm{z} 5=0.102$ & $\mathrm{z} 6=0.122$ \\
\hline $\mathrm{x} 1=0.03 \mathrm{~m}$ & 8871.3 & 8972.2 & 8216.8 & 5301.3 & 5633 & 10621 \\
\hline $\mathrm{x} 2=0.1335 \mathrm{~m}$ & 13468 & 7576.1 & 7252.4 & 14502 & 8077.2 & 7613 \\
\hline $\mathrm{x} 3=0.237 \mathrm{~m}$ & 10248 & 10938 & 11740 & 8768.7 & 11305 & 17366 \\
\hline
\end{tabular}

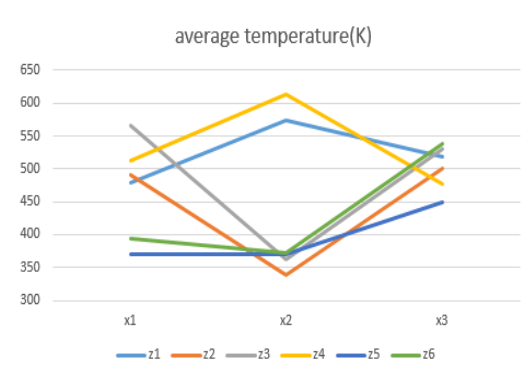

a

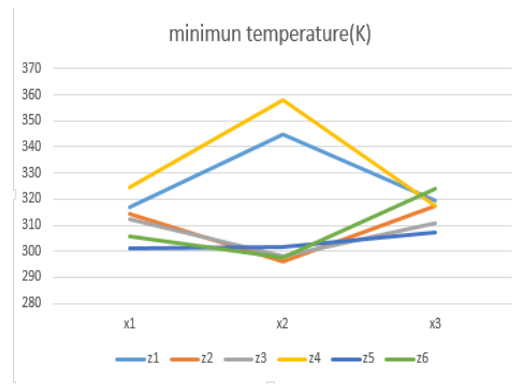

b

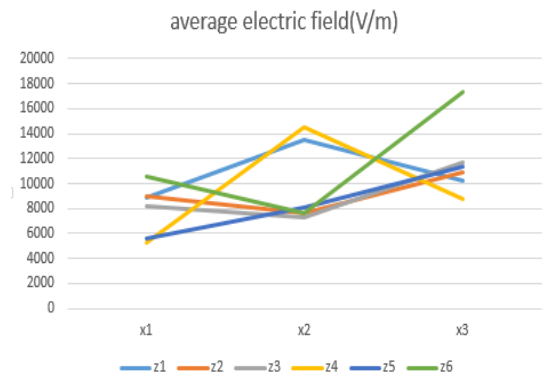

$\mathrm{c}$

Figure 17- a) Average temperature inside coal b) Minimum temperature inside coal c) Average electric field inside the cavity.

Among the six factors mentioned, i.e., coal moisture capacity, frequency, input power, waveguide location, waveguide dimensions, and coal location, the dimensions of the chamber is one of the most important factors affecting the distribution of the electric and thermal fields. In fact, the chamber walls form the boundary conditions of the system and affect the resonant frequency of the chamber. Therefore, the tests performed in the next part were repeated in a chamber with different dimensions to validate the results.

\section{Changing Cavity Size}

The dimensions of the resonance chamber are one of the most basic parameters affecting the resonance frequencies and consequently, the electric and thermal field distribution inside the chamber and coal [16]. Therefore, to demonstrate the reliability of the obtained results, it is necessary to consider a chamber with different dimensions. The dimensions of the new chamber are $296 * 366 * 302 \mathrm{~mm}$ [16]. The coal, with moisture capacity of $4.7 \%$, input port power of 1000 watts, and operating frequency of $2.45 \mathrm{GHz}$, was placed in the chamber for 300 seconds. The dimensions of the waveguide, glass plate, and coal are summarized in Table 3 . The height of the waveguide port from the bottom of the chamber is 0.021 meters so that the electric and thermal field of the coal is the same as in the previous chamber (Figure 4). The structure of the new chamber is shown in Figure 18.

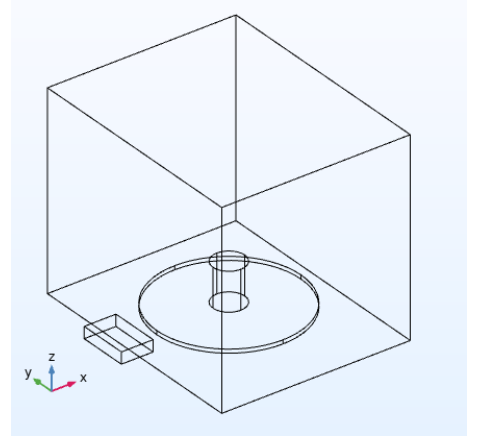

Figure 18- Coal placement in the second chamber.

The electric and thermal fields inside the chamber and the coal are shown in Figure 19. 


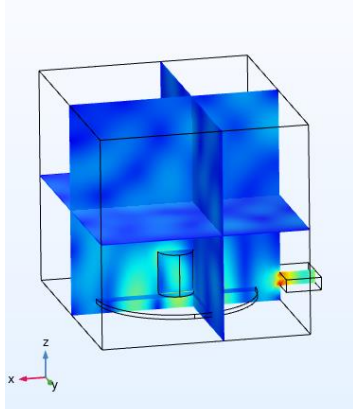

a

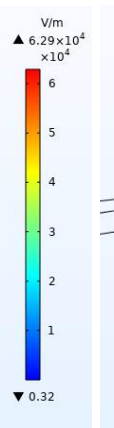

$\left.y_{2}^{2}\right\rfloor^{2}$

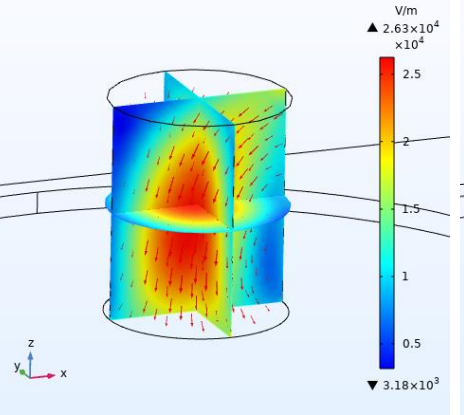

b

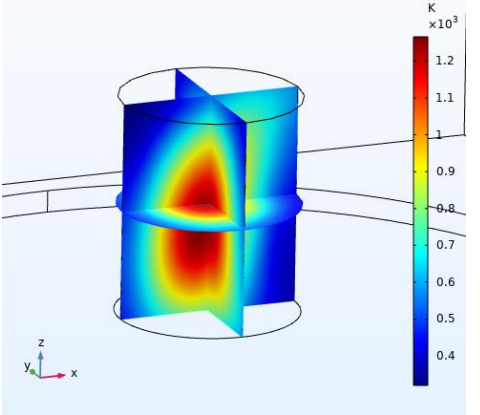

c

Figure 19- a) Electric field inside the chamber b) Electric field inside the coal c) Temperature inside the coal (K).

The parameters were changed one at a time following the same procedure as in the previous section.

\subsection{Coal moisture capacity}

Specific moisture capacity, diffusion coefficient, and permittivity of coals were set according to Table 4 . Figures 20 and 21 show the effect of increasing coal moisture on the electric and thermal field distribution. As in the previous chamber, a moisture of $5 \%$ leads to the highest temperature increase in coals.

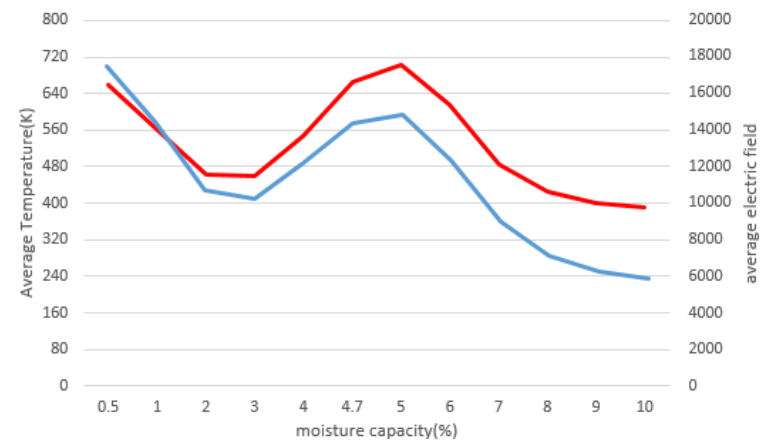

Figure 20- Blue indicates the average electric field inside coal and red indicates the average temperature inside coal

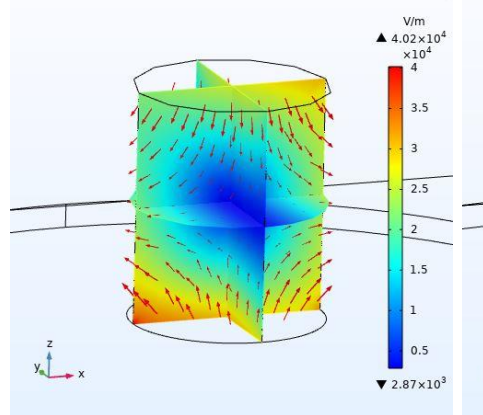

a

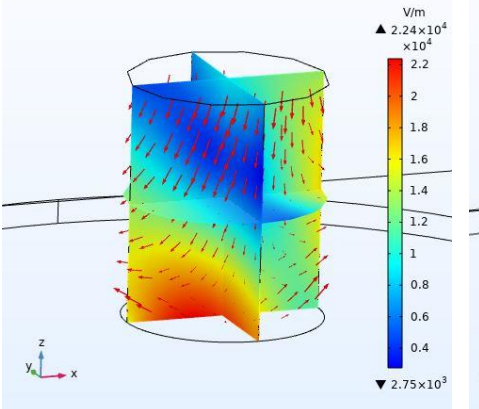

$\mathrm{b}$

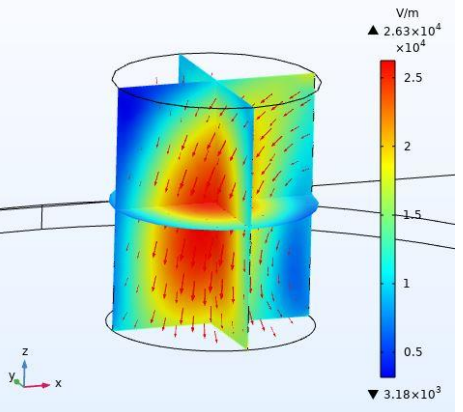




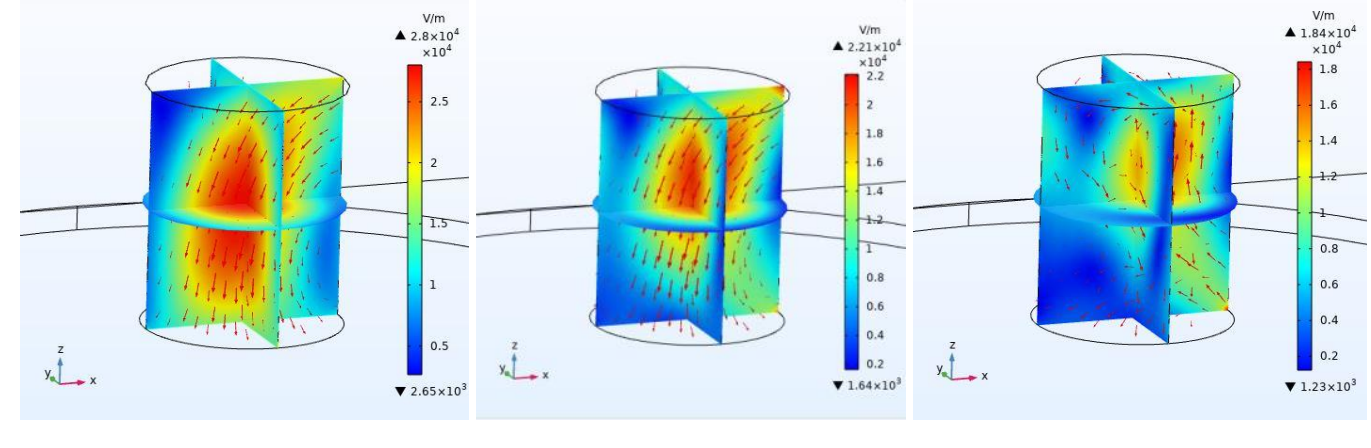

d

e

f

Figure 21- Electric field inside coal with the moisture capacity of a) $0.5 \%$ b) $2 \%$ c) $4.7 \%$ d) $5 \%$ e) $7 \%$ f) $10 \%$.

\subsection{Microwave frequency}

Figure 22 shows the effect of varying frequency from 1.9 to $3.8 \mathrm{GHz}$ (with a distance of 0.1 ) on the electric and thermal fields inside the coal specimen. Uniform electric and thermal fields in coal frequency were obtained for 2.1 $\mathrm{GHz}$ while the highest temperature increase in coal was shown for a frequency of $3.5 \mathrm{GHz}$ and the lowest temperature increase for $2.2 \mathrm{GHz}$. Note that these values are different from those obtained in section 5.2.

Figures 23 and 24 also show four frequency examples.

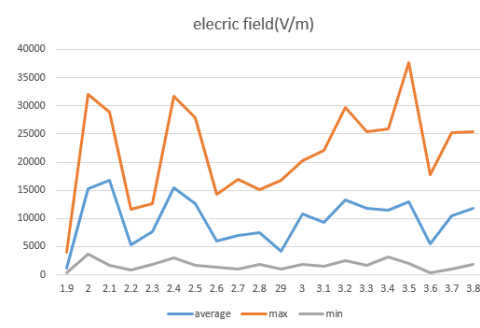

a

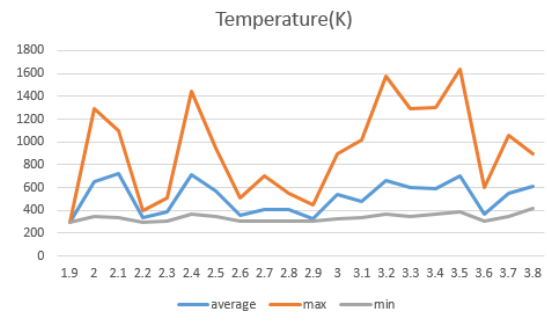

b

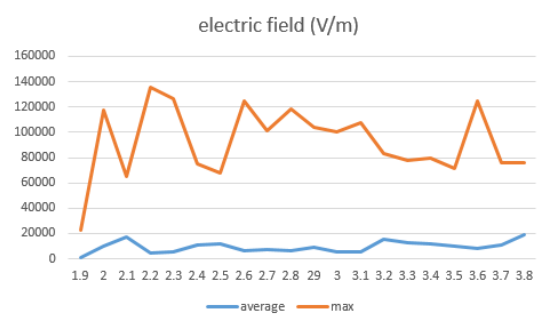

$\mathrm{c}$

Figure 22- a) Average, maximum and minimum electric field inside the specimen in the frequency range of 1.9 to $3.8 \mathrm{GHz}$ b) Average, maximum and minimum temperature in the coal specimen in the frequency range of 1.9 to $3.8 \mathrm{GHz}$ ) Maximum and average electric field inside the cavity.

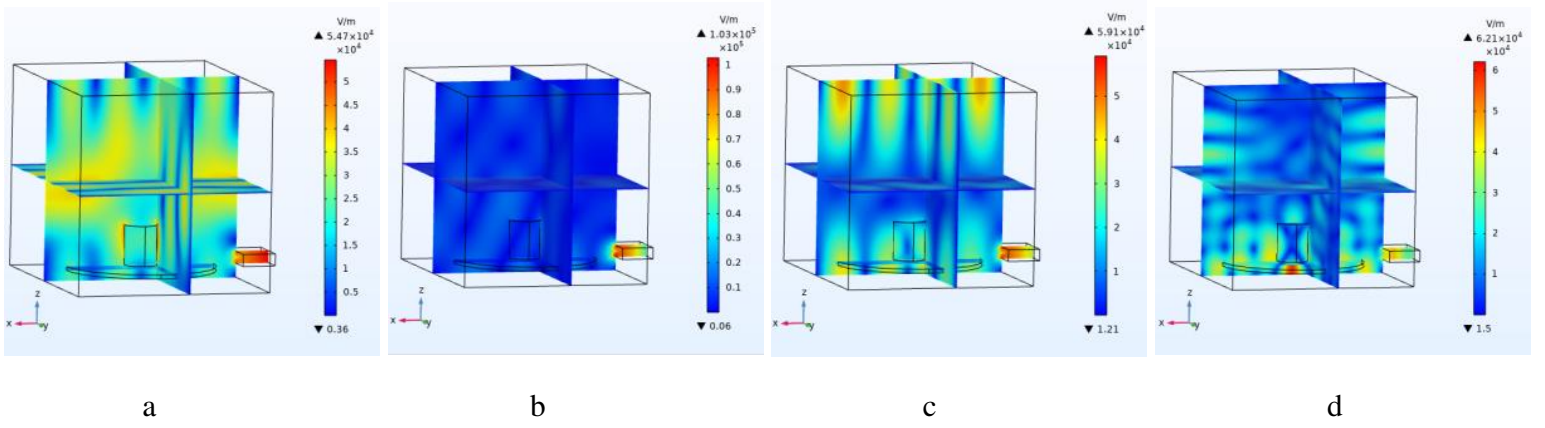

Figure 23- Electric field inside the cavity at the frequency of a) $2.1 \mathrm{GHz}$ b) $2.2 \mathrm{GHz}$ c) $2.4 \mathrm{GHz}$ d) $3.5 \mathrm{GHz}$. 


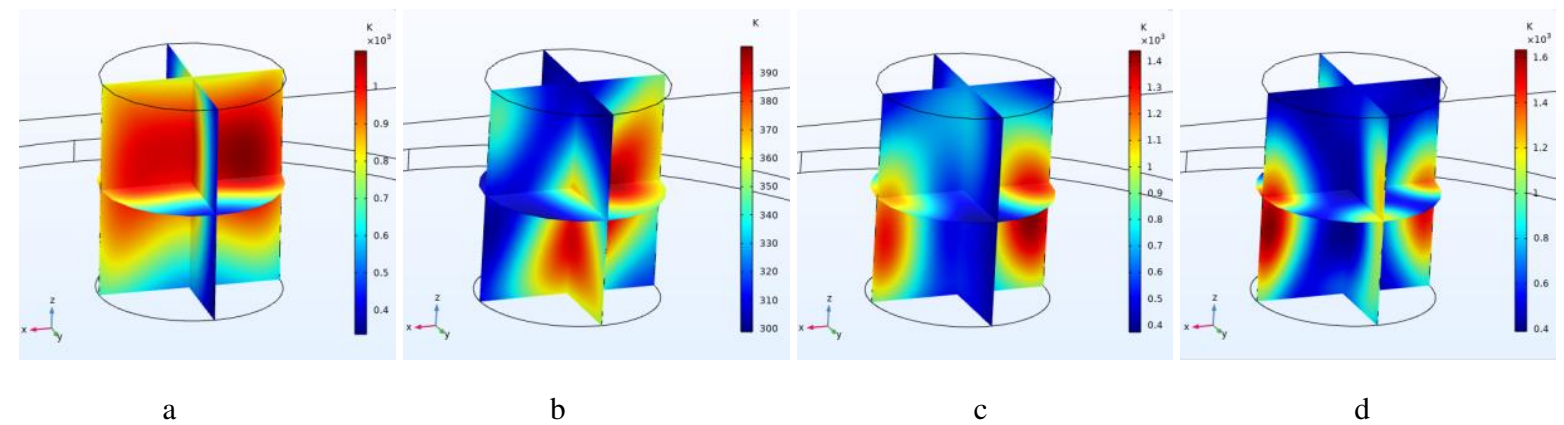

Figure 24- Coal temperature at the frequency of a) $2.1 \mathrm{GHz}$ b) $2.2 \mathrm{GHz} \mathrm{c)} 2.4 \mathrm{GHz}$ d) $3.5 \mathrm{GHz}$.

\subsection{Microwave Time and Power}

This section investigates the effect of input power on the electric field and heat of the system. To make the specimens comparable in terms of heat, the input energy was assumed constant and equal to $300 \mathrm{~kJ}$. The input power was set according to Table 5 and the results compared. According to Figures 25 and 26, the electric field distribution does not depend on the amount of input power, and only the electric field size increases in proportion to the square root of the input power, which confirms the results obtained with the smaller cavity (Section 5.3).

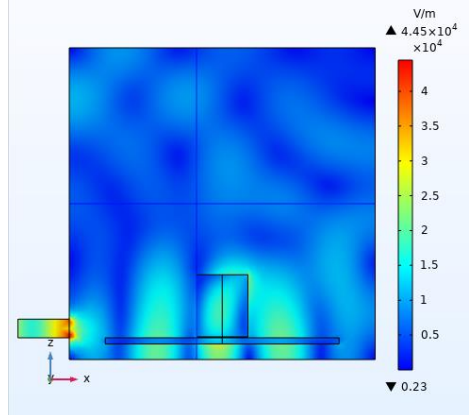

a

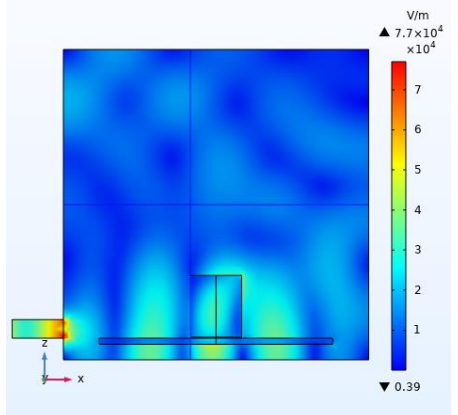

b

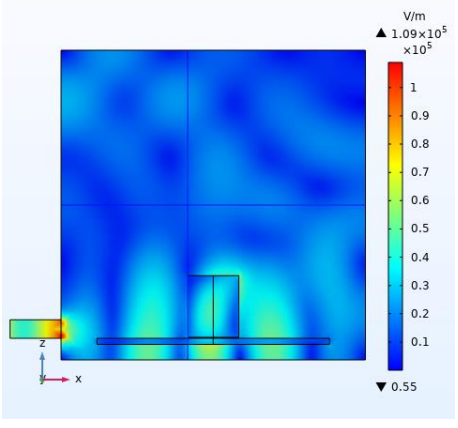

$\mathrm{c}$

Figure 25- Electric field inside the cavity with the input port power of a) 500 watts b) 1500 watts c) 3000 watts.

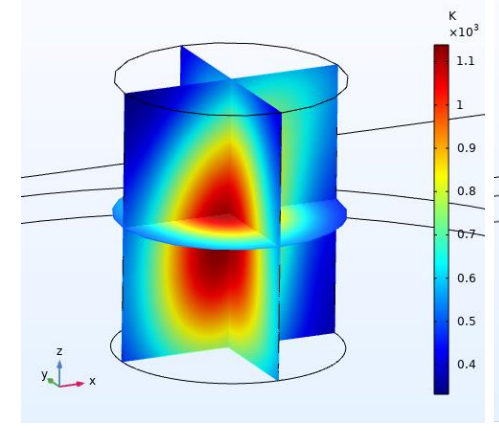

a

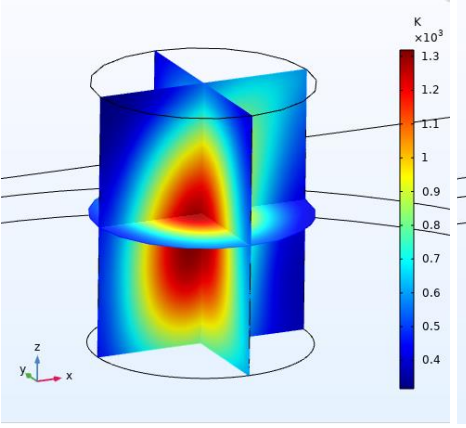

b

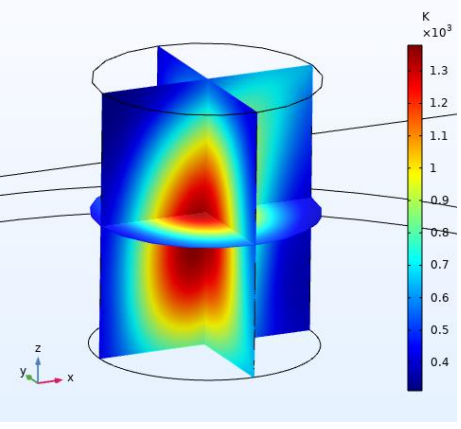

c

Figure 26- Temperature inside coal with the input port power of a) 500 watts b) 1500 watts c) 3000 watts.

\subsection{Waveguide place}

In this section, the waveguide height is varied. Figure 27 shows the effect of increasing the microwave port height on the average electric field of the cavity and the maximum and average thermal field of coal. The height of $0.051 \mathrm{~m}$ gave 
the lowest temperature increase rate while an height of $0.17 \mathrm{~m}$ produced the highest temperature increase rate inside the coal.

Figure 27.a indicates that the change in the height of the waveguide causes oscillating changes in the average electric field of both chambers. Figure 28 shows the distribution of electric and thermal fields at the altitudes of $0.017,0.034$, $0.136,0.285$ meters.

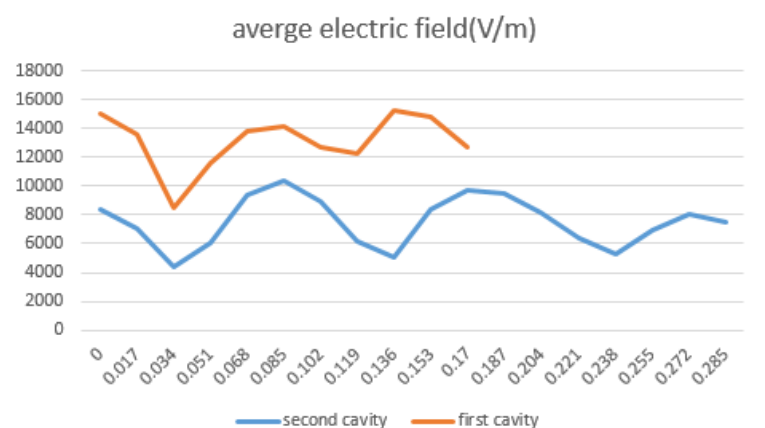

a

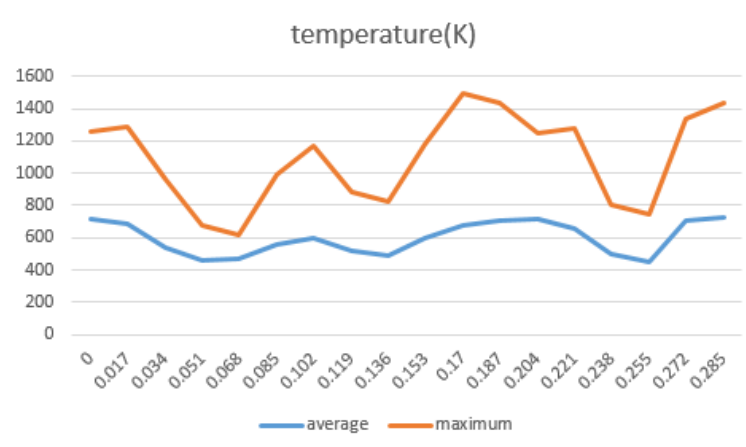

$\mathrm{b}$

Figure 27-a) The effect of increasing the height of the microwave port with a step of 0.017 meters on the average electric field inside the cavity and its comparison with the first cavity b) Maximum and average coal temperature.

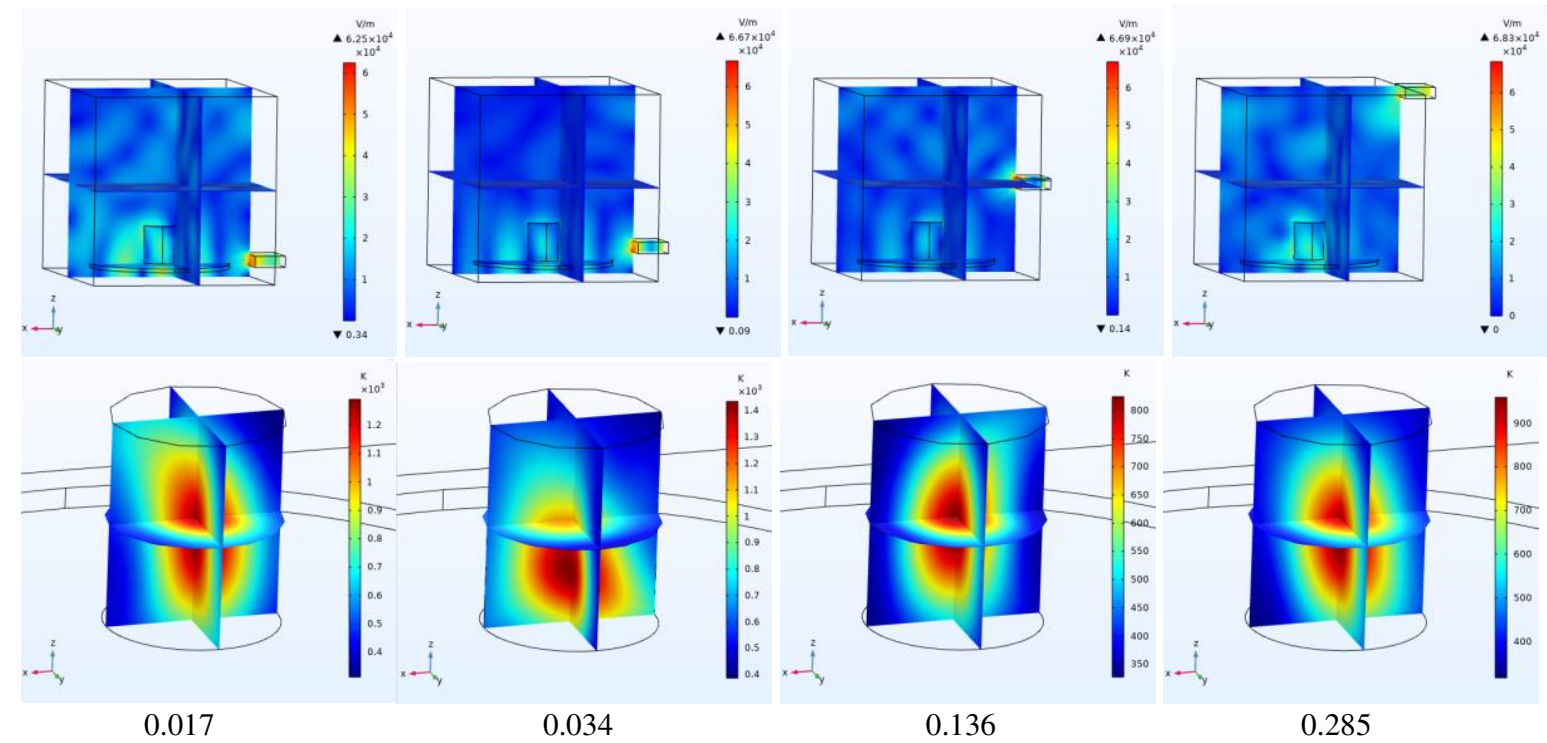

Figure 28- Electric and thermal fields inside the cavity and coal vs. the height of the waveguide port.

\subsection{Waveguide size}

The dimensions of the waveguide were changed one at a time to investigate the effect of waveguide size (Table 8). As can be seen in Figure 29 and 30, by changing the dimensions of the waveguide, the distribution of the field inside the cavity does not change significantly. However, when the cutoff frequency of the waveguide is close to the operating frequency $(2.45 \mathrm{GHz})$, the size of the electric field in the cavity and the coal and, consequently, the size of the thermal field inside the coal increase, similarly to what we obtained with the previous cavity (Section 5.5). Figure 31 shows that with increasing wavelength, the average electric field inside the cavity and the average temperature inside the coal decrease.

Table 8- Dimensions of the tested waveguides

\begin{tabular}{|l|l|l|l|l|l|}
\hline Waveguide & 1 & 2 & 3 & 4 & 5 \\
\hline
\end{tabular}




\begin{tabular}{|c|c|c|c|c|c|}
\hline width(m) & 0.078 & 0.078 & 0.078 & 0.064 & 0.091 \\
\hline Height $(\mathrm{m})$ & 0.018 & 0.039 & 0.018 & 0.018 & 0.018 \\
\hline Depth(m) & 0.05 & 0.05 & 0.1 & 0.05 & 0.05 \\
\hline
\end{tabular}

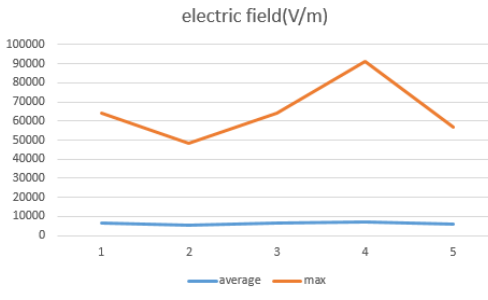

a

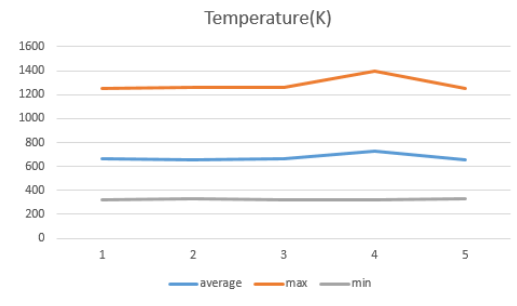

b

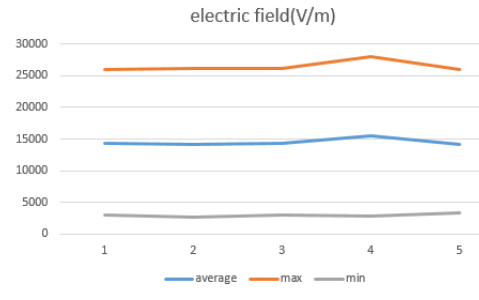

c

Figure 29- a) Average, maximum and minimum electric field in coal b) Maximum and average electric field in the whole cavity c) Average, maximum and minimum thermal field in coal.

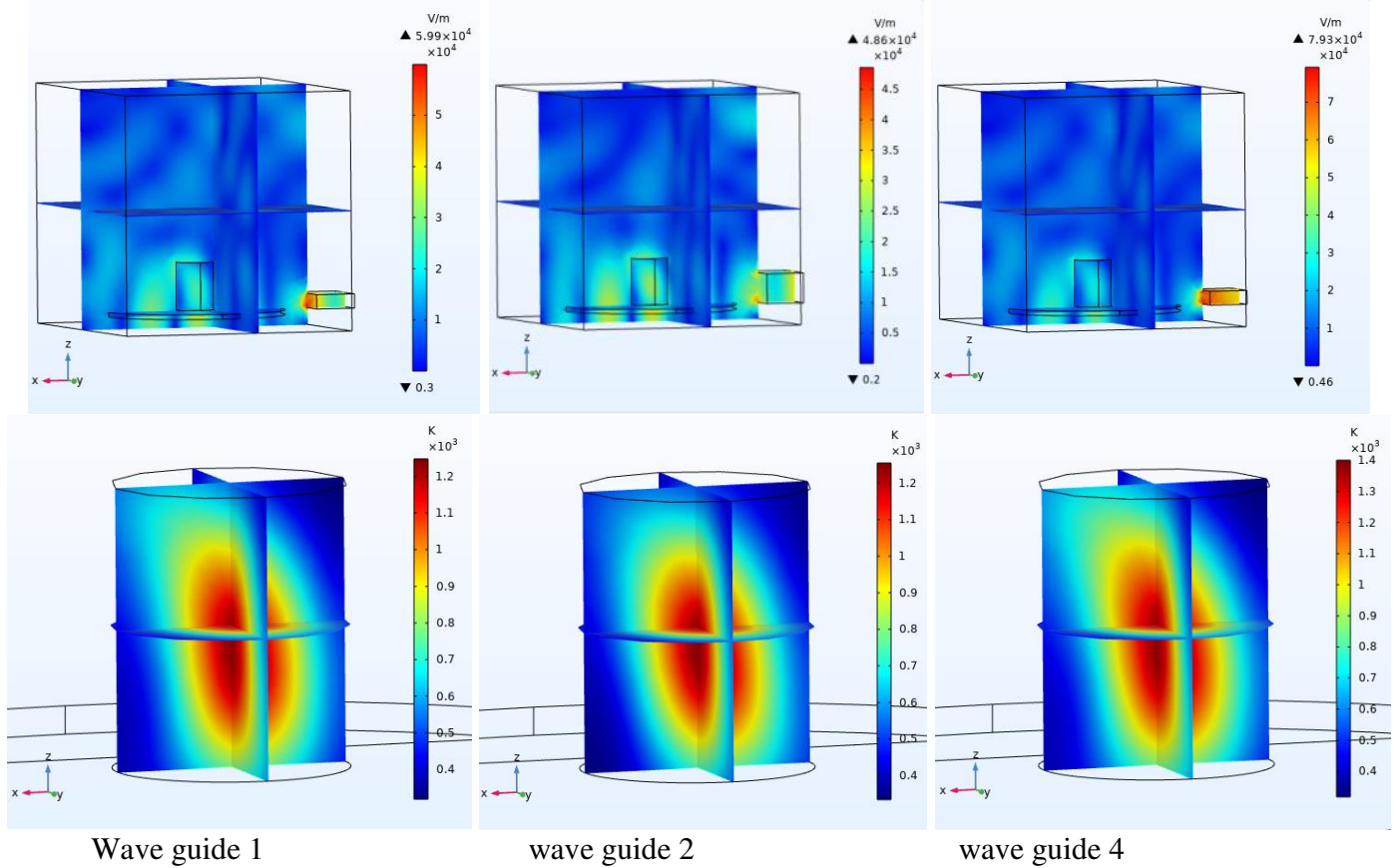

Figure 30- Electric field of the cavity with waveguide No. 1, 2 and 4 and thermal field in coal corresponding to waveguide No. 1, 2 , and 4 .

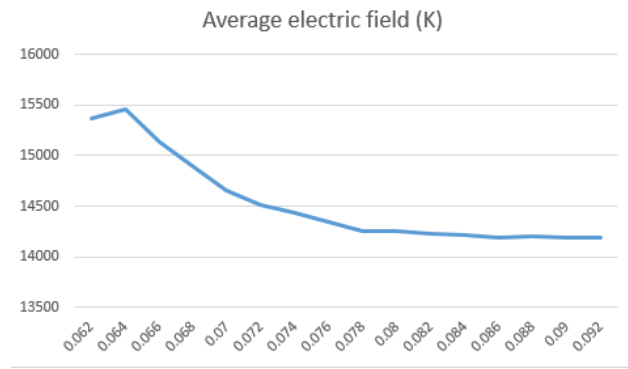

a

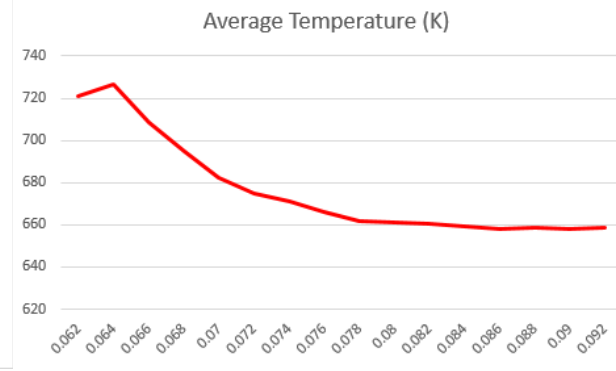

b

Figure 31- a) The average electric field inside the chamber and b) the average coal temperature that decrease with increasing waveguide width.

\subsection{Place of Coal}


Another factor that affects the electric and thermal field distribution inside the chamber is the place of the coal inside it. According to Table 9, the height of the coal bottom ( $\mathrm{z}$ ) and the distance of the coal from the waveguide (x) were varied. According to Figure 32, the place of coal (x3, z6) has the highest average temperature rise and the densest temperature occurs at $(\mathrm{x} 1, \mathrm{z} 1)$, i.e., like in the previous chamber, while the highest temperature rise and highest thermal field density happened when the coal is attached to the end of the waveguide. As in the previous chamber, the highest temperature rise and the highest thermal field density occurred when the coal is attached to the waveguide aperture; but no clear relationship was observed between the place of coal and the electric and thermal field distribution inside the coal.

Table 9- Maximum electric field in terms of coal displacement.

\begin{tabular}{|c|c|c|c|c|c|c|}
\hline & $\mathrm{z} 1=0.022$ & $\mathrm{z} 2=0.042$ & $\mathrm{z} 3=0.062$ & $\mathrm{z} 4=0.082$ & $\mathrm{z} 5=0.102$ & $\mathrm{z}=0.122$ \\
\hline $\mathrm{x} 1=0.03 \mathrm{~m}$ & 48921 & 17035 & 12489 & 17755 & 18440 & 12992 \\
\hline $\mathrm{x} 2=0.1485 \mathrm{~m}$ & 25998 & 15330 & 16072 & 17902 & 14317 & 14453 \\
\hline $\mathrm{x} 3=0.267 \mathrm{~m}$ & 22924 & 18672 & 13708 & 15357 & 28802 & 23911 \\
\hline
\end{tabular}

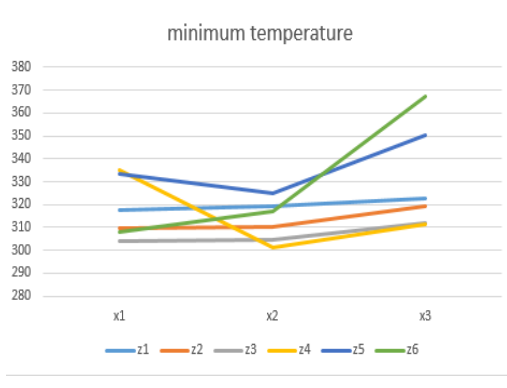

a

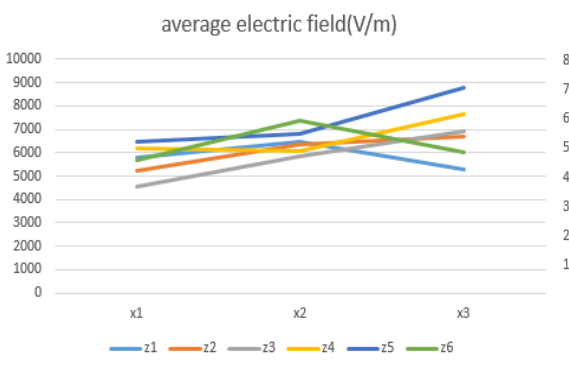

b

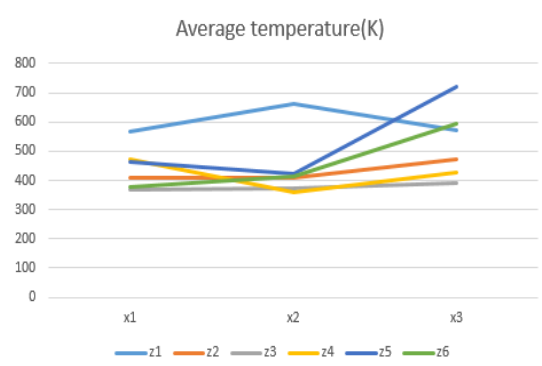

$\mathrm{c}$

Figure 32- a) Average temperature inside coal b) Minimum temperature inside coal c) Average electric field inside the cavity.

A comparison between the tests performed in the chamber indicates that the moisture of 5\%, the highest input power (3000 watts), and a cutoff frequency close to the operating frequency cause the highest average temperature inside the coal. However, the appropriate operating frequency, the right waveguide location, the suitable coal place vary depending on the size of the chamber.

\section{Conclusion}

Methane gas in coal is one of the most hazardous flammable and explosive agents in coal mines. Therefore, to prevent explosions and risk of methane accumulation and to prevent environmental pollution, it is necessary to extract methane gas during coal mining operations. The use of microwave radiations is one of the most up-to-date methods of extracting methane gas in coal. For this purpose, this paper examined the parameters affecting the electric and thermal field distribution in both the coal and the microwave chamber with the aim to obtain suitable conditions for the extraction of methane gas in coal. The results showed mostly that the highest average temperature inside the coal can be obtained with 5\% moisture and a cutoff frequency close to the working frequency. However, many parameters such as operating frequency, location of waveguide and location of coal should be explored depending on the size of the chamber, knowing that the most significant parameters that affect the electric and thermal fields of coal are the dimensions of the resonant chamber.

Acknowledgments: The authors acknowledge the NSERC (Grant No. NSERC ALLRP561048-20, and CRDPJ 537378-18) and Minister of Economic Development, Trade and Tourism (through Major Innovation Project) for funding this project.

Availability of data and materials: All data generated or analyzed during this study are included in this published paper. 


\section{Declaration Conflict of interest}

The authors declare that they have no conflict of interest

Open Access: This article is licensed under a Creative Commons Attribution 4.0 International License, which permits use, sharing, adaptation, distribution and reproduction in any medium or format, as long as you give appropriate credit to the original author(s) and the source, provide a link to the Creative Commons licence, and indicate if changes were made. The images or other third party material in this article are included in the article's Creative Commons licence, unless indicated otherwise in a credit line to the material. If material is not included in the article's Creative Commons licence and your intended use is not permitted by statutory regulation or exceeds the permitted use, you will need to obtain permission directly from the copyright holder. To view a copy of this licence, visit http://creativecommons.org/licenses/by/4.0/.

\section{References}

[1] Eleanor Binner, Edward Lester, Sam Kingman, Chris Dodds, John Robinson, Tao Wu, Peter Wardle \& Jonathan P. Mathews, A Review of Microwave Coal Processing, Journal of Microwave Power and Electromagnetic Energy, 48:1 (2014) 35-60.

[2] Coronel, Pablo, Continuous flow processing of foods using cylindrical applicator microwave systems operating at $915 \mathrm{MHz}$, North Carolina State University (2006).

[3] Huang, Jinxin, Guang Xu, Guozhong Hu, Mehmet Kizil, and Zhongwei Chen. A coupled electromagnetic irradiation, heat and mass transfer model for microwave heating and its numerical simulation on coal, Fuel Processing Technology, 177 (2018) 237245.

[4] Chemat, Farid, Microwave-assisted extraction for bioactive compounds, Springer US, New York, 2012.

[5] Baiquan Lin, He Li, Zhongwei Chen, Chunshan Zheng, Yidu Hong, Zheng Wang, Sensitivity analysis on the microwave heating of coal: A coupled electromagnetic and heat transfer model, Applied Thermal Engineering, 126 (2017) 949-962.

[6] Zhiwei Peng, Xiaolong Lin, Zhizhong Li, Jiann-Yang Hwang, Byoung-Gon Kim, Yuanbo Zhang, Guanghui Li, Tao Jiang, Dielectric characterization of Indonesian low-rank coal for microwave processing, Fuel Processing Technology, 156 (2017) 171177.

[7] Pozar, David M., Microwave Engineering third ed., Wiley, 2009.

[8] Ali Jebelli, Arezoo Mahabadi, Mustapha C. E. Yagoub, Hicham Chaoui, Magnetic Force Calculation between Magnets and Coils, International Journal of Physics, 8:2 (2020) 71-80.

[9] Ali Jebelli, Arezoo Mahabadi, Hicham Chaoui and Mustapha C. E. Yagoub, Simulation of Magnetic Force between Two Coaxial Coils with Air Core and Uniform Flow in MATLAB, International Journal of Physics, 9:4 (2021) 186-196.

[10] Rajiv Kumar Vashisht, Qingjin Peng, Efficient active chatter mitigation for boring operation by electromagnetic actuator using optimal fractional order PD $\lambda$ controller, Journal of Materials Processing Technology, 276 (2020) 116423.

[11] Lin, Baiquan, He Li, Zhongwei Chen, Chunshan Zheng, Yidu Hong, and Zheng Wang, Sensitivity analysis on the microwave heating of coal: A coupled electromagnetic and heat transfer model, Applied Thermal Engineering, 126 (2017) 949-962.

[12] Ziyu Shao, Yujie Wang, Hao Bai, A superhydrophobic textile inspired by polar bear hair for both in air and underwater thermal insulation, Chemical Engineering Journal, 397,125441 (2020).

[13] Ghalichia, F., S. Behniab, and E. Sadigh Radb, Calculations for Ultrasonic Transducer Design and Temperature Tracking for Hyperthermia in Cervical Cancer, Iranian Conference on Biomedical Engineering, 11 (2004).

[14] Chungang Zhuang, Zhenhua Xiong, Han Ding, Temperature-constrained topology optimization of nonlinear heat conduction problems, Journal of Computational Design and Engineering, 8:4 (2021) 1059-1081.

[15]Mitrović, Miranda, and Branka Jokanović, Field tunneling and losses in narrow waveguide channel, Microwave Review 16:2 (2010) 8-13.

[16] Harold S. Hauck, Design Considerations for Microwave Oven Cavities, IEEE Transactions on Industry and General Applications, IGA-6:1 (1970) 74 - 80. 
[17] Qi Xia, Tielin Shi, Multiphysics Topology Optimization of Thermal Actuators by Using the Level Set-Based Multiple-Type Boundary Method, International Journal of Computational Methods, 17:8 (2020) 1950044.

[18] D.V. Miroshnichenko, I. V. Shulga, Yu. S. Kaftan, N. A. Desna \& Yu. V. Nikolaichuk, Ignition temperature of coal 3. Multicomponent coal mixtures, Coke Chemistery. 60 (2017) 343-347.

[19] Fabian Wein, Peter D. Dunning, Julian A. Norato, A review on feature-mapping methods for structural optimization, Structural and Multidisciplinary Optimization, 62 (2020) 1597-1638.

[20] Alberto Álvarez-Trejo, Enrique Cuan-Urquizo, Armando Roman-Flores, L.G. Trapaga-Martinez, J.M. Alvarado-Orozco, Bézier-based metamaterials: Synthesis, mechanics and additive manufacturing, 199 (2021) 109412.

[21] Tombe, Frederick David, The Significance of the Poynting Vector, The General Science Journal, United Kingdom (2020).

[22] Milovanović Bratislav, Joković Jugoslav, Dimitrijević Tijana, Analysis of feed waveguide length influence on EM field in microwave applicator using TLM method AU, Facta universitatis, series: Electronics and Energetics, 21:1 (2008) 65-72. 